\title{
ÜBER DAS
}

\section{WACHSTUM DES MENSCHLICHEN AUGES}

UND ÜBER DIE

VERÄNDERUNG DER MUSKELLNSERTIONEN

AMI

WACHSENDEN AUGE.

VON

PROF. L. WEISS,

HETDELBERG.

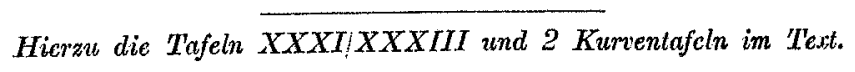



Die Angaben, welche man über die Wachstumsverhältnisse des Auges in den bekannteren Lehrbüchern findet, sind zum Teil unvollständig, zum Teil auch direkt widersprechend. Unter solchen Umständen schien mir eine neuerliche Bearbeitung dieses Gegenstandes angezeigt, und dies um so mehr, als derselbe neben dem allgemeinen anatomischen, auch noch ein speziell augenärztliches Interesse darbietet ${ }^{1}$ ), nachdem vor einiger Zeit die Ansicht ausgesprochen worden ist, dass den Wachstumsverhältnissen des Auges bei gewissen pathologischen Zuständen eine wichtige Rolle zukäme. So wurde von Samelsohn ${ }^{2}$ ) auf dem Ophthalmologenkongress 1894, anschliessend an meinen Vortrag über das Schielen und seine Spontanheilung, die Behauptung aufgestellt, dass für die Frage der Selbstheilung des Strabismus convergens das Wachstum des kindlichen Bulbus, insbesondere die damit verbundenen Veränderungen der Muskel-Insertionen von wesentlichem Einfluss sein dürften. Da ich damals bereits eine Reihe von jugendlichen Augen der verschiedensten Lebensalter untersucht hatte, konnte ich dem gegenüber sofort hervorheben, dass die Spontanheilung des Schielens gewöhnlich im 16. u. 17. Lebensjahr, also zu einer Zeit stattfindet, in welcher das Wachstum des Auges und damit die Veränderungen der

1) Auch die Entwickelung der Myopie wird neuerdings als ein durch äussere Momente verändertes Wachstum des Auges gedeutet.

2) Ber. d. 23. Vers. d. Ophthalm.-Ges., pag. 136. 
Muskel-Insertionen der Hauptsache nach schon lange abgeschlossen sind. Die Zahl meiner damaligen Untersuchungen, auf die ich mich hierbei stützen konnte, war verhältnismässig klein. Es schien mir von Wert, die Wachstumsverhältnisse des kindlichen Auges durch umfangreichere Untersuchungen einer eingehenderen Prüfung zu unterziehen. Das hierzu nötige anatomische Material hatte ich im Laufe der Jahre gesammelt. Meine Sammlung enthielt eine grosse Anzahl von Augen von Neugeborenen, von Kindern der verschiedensten Lebensalter und von Erwachsenen, bei welch letzteren der Refraktionszustand zu Lebzeiten festgestellt worden war.

Das Ergebnis dieser Untersuchungen soll in folgendem der Hauptsache nach in Kürze mitgeteilt werden.

Was den Gang der Untersuchung betrifft, so war derselbe folgender:

Nach gründlicher, schonender Präparation des Bulbus, insbesondere der Muskelinsertionen wurden die Muskeln, bezw. deren Sehnen unweit der Insertion an der Sklera abgeschnitten. Um das Zeichnen und Messen zu erleichtern, wurden die Sehnen der Muskeln nach vorn umgeklappt, so dass die hintere Insertionslinie anschaulicher hervortrat. Die Zeichnungen wurden in bekannter Weise mit Hülfe des Lucäschen Apparats aufgenommen und zwar bei jedem Bulbus von oben, von unten, von der nasalen und von der temporalen Seite. Sodann wurde der Bulbus gewogen und zwar zuerst in Luft und dann unter Wasser. Auf diese Weise wurde das Gewicht, das Volumen und das spexifische Gewicht bestimmt. Erwähnt sei hier noch, dass an allen Bulbis, welche sämtlich in Müllerscher Flüssigkeit gehärtet waren, der Sehnerv kurz hinter dem Bulbus abgeschnitten war. Die übrigen Messungen geschahen in folgender Weise: Es wurden die Durchmesser des Bulbus in drei Dimensionen bestimmt, sagittal, horizontal und vertikal, desgl. der Umfang horizontal, vertikal und äquatorial. Für das Mass der Sehnen- 
breiten wurde der gerade Abstand ihrer Endpunkte genommen. Der bogenförmige Verlauf der Insertionen, welcher besonders beim Obliquus superior häufig auffallend stark ist, wurde auf diese Weise freilich ausser acht gelassen, fand jedoch Berücksichtigung bei Messung des geraden Abstandes der Insertionen vom Hornhautrande, indem bei dieser an verschiedenen Stellen der Insertion, nämlich für die beiden Endpunkte und für die Mitte der Abstand bestimmt wurde. In gleicher Weise wurde für die sämtlichen Muskelinsertionen der direkte Abstand vom Sehnerven gemessen. Ferner wurde bei den beiden Obliquis unter anderem noch die Entfernung je der beiden vorderen und hinteren Insertionsenden von einander gemessen. Um die Lage der Insertionen des Rectus internus und externus zur Horizontalebene zu bestimmen, wurde ein Faden horizontal um den Bulbus gelegt. Die Insertionen wurden durch diesen Faden in je ein oberes und unteres Stück geteilt und die einzelnen Teilstücke gemessen. Endlich wurde noch für die Insertionen von Externus und Internus der Bogenabstand gemessen vom Hornhautrande einerseits, von der Eintrittsstelle des Sehnerven andererseits und zwar jeweils für die Mitte der Insertion. Zu diesem Zwecke wurde ein schmaler dünner Papierstreif horizontal um den Bulbus gelegt, so dass derselbe der Sklera überall dicht anlag; an den betreffenden Messungspunkten, nämlich Insertionsmitte, Optikus und Hornhautrand wurden dann mit der Schere kleine Einschnitte in den Papierstreif gemacht. Der Papierstreif wurde dann auf einen feinen Massstab gelegt und die entsprechenden Entfernungen wurden hier abgelesen. Kleine Fehler waren bei diesen Messungen selbstverständlich nicht ganz zu vermeiden. Für die beiden Obliqui wurde auch noch der Abstand der Insertionsendpunkte von dem Äquator und von dem Horizontal- bezw. von dem Vertikalmeridian bestimmt.

Zunächst wurde die Form und Grösse des Auges des Neugeborenen festgestellt mit besonderer Berücksichtigung des $V_{\text {er- }}$ 
haltens der Muskel-Insertionen. Im ganzen kamen 14 Augen von Neugeborenen im Alter von 1-5 Tagen zur Untersuchung. In allen Fällen handelte es sich um ausgetragene Kinder, deren Gewicht und Körperlänge den Durchschnittswerten entsprach. Die Augen waren in $M$ üller scher Flüssigkeit gehärtet und sämtlich in der Form gut erhalten. Von den bei diesen 14 Fällen erhaltenen Messungswerten wurden jeweils die Mittelzahlen berechnet. Sodann wurden in gleicher Weise 5 Augen von emmetropischen Erwachsenen untersucht, deren Refraktion intra vitam bestimmt worden war und auch hier die Mittelzahlen berechnet. Ein Vergleich der bei beiden Untersuchungsreihen erhaltenen Mittelwerte ergab das Mass des Gesamtwachstums des Auges.

Um nun weiter zu erfahren, wie sich das Wachstum des Auges auf die verschiedenen Lebensabschnitte verteilt, wurde eine grössere Anzahl von Augen kindlicher und jugendlicher Individuen der verschiedensten Lebensalter untersucht und das Verhältnis ihrer Masse zu denen des Neugeborenen berechnet und zwar in der Weise, dass das betreffende Mass des Neugeborenen gleich 1 gesetzt wurde.

Das Ergebnis der Untersuchungen, bei welchen mich mein früherer Assistent, Herr W. Ottinger, unterstützte, soll in drei Abschnitten mitgeteilt werden.

Im ersten Abschnitt wird Volumen und Gewicht des Bulbus behandelt, im zweiten Durchmesser und Umfang desselben, je nach drei Dimensionen und im dritten Abschnitt das Verhalten der Muskel-Insertionen. 


\section{Volum und Gewicht des Bulbus.}

\section{Über Volum und Gewicht des Auges in den verschiedenen} Lebensperioden finden sich in den Lehrbücheru ${ }^{1}$ ) u. a. folgende Angaben:

Nach Meckel ${ }^{2}$ ) ist der Augapfel früher verhältnismässig grösser als in späteren Lebensperioden, die Hornhaut ist beim Fötus noch einmal so dick als beim kirwachsenen.

Kingehende Angaben über Form, Grösse and Gewicht des Auges bei Erwachsenen und Kindern finden sich bei Sömmering ${ }^{3}$ ). Was die Form des Auges betrifft, so heisst es daselbst:

${ }_{n}$ Der Apfel ist von vorn nach hinten etwas zusammengedrückt, was im Finklang mit der Wirkung der geraden Augenmuskeln steht, und zweitens schief von aussen oben nach unten innen kürzer und mehr komprimiert, als wie in der entgegengesetzten Richtung.

„Das Volum des Apfels beträgt nach Krause ungefähr 1/3 Kubik-Zoll, doch ist seine Grösse Schwankungen unterworfen. Es wird darauf aufmerksam gemacht, dass die Grösse des Auges beim Lebenden oft falsch taxiert wird. Auf diese scheinbare Grösse haben Einfluss die tiefere oder oberflichlichere Lage des Apfels, die mit der Grösse des Fettpolsters in Verbindung steht, die Weite der Augenlidspalte (je grösser sie ist, desto grösser scheint der Augapfel zu sein and umgekehrt), die Länge der Bindehautfalte, und endlich die Grösse der Hornhaut, welche zuweilen grösser ist im Verhältnis zur Sklerotika, als gewöhnlich und dann den Schein eines grösseren Bulbus macht." Weiter heisst es daselbst:

„Das absolute Gewicht fand ich in unserer Gegend obne die Augenmuskeln und den Sehnerven $=6600-8200 \mathrm{mg}$, Krause 104-128 Gran $(=6240-7680 \mathrm{mg}$ ), Petit 142 Gran $=8520 \mathrm{mg}$ (wobei aber wohl der Sehnerv ist). Nicht so selten ist bei Erwachsenen, selten bei Kindern der eine Apfel um einen Gran schwerer als der andere, der dann wohl der fernsichtigere sein möchte. Der Augapfel scheint auch urm so grösser, schwerer, kräftiger zu werden, $j \theta$ südlicher die Menschen; wenn der Apfel eines Europäers $133 \mathrm{Gran}=7980 \mathrm{mg}$ wiegt, so wiegt ein Negerauge 142 Gran $=8520 \mathrm{mg}$; die Dicke und Schwärze des eisenreichen Pigments geben hierbei wohl den Grund mit ab."

Das spezifische Gewicht wird zwischen 1,022 und 1,032 angegeben.

1) Die nachfolgende Litteraturzusammenstellnng will keinen Anspruch auf Vollständigkeit erheben, sie enthält nur die Angaben derjenigen Werke, welche mir zugänglich waren.

2) Meckel, Mensohl. Anat. 1820. Bd. IV, pag. $105 \mathrm{ff}$.

i) Samuel Thomas v. Sömmering, Lehre von den Eingeweiden und Sinnesorganen. Umgearbeitet und beendigt von E. Huschke 1844.

Anatomische Hofte. I. Abteilung. XXV. Heft (8. Bd. H. 2). 
Bezüglich der Geschlechtsversehiedenheiten wird angegeben, dass das weibliche Sehorgan im allgemeinen kleinere absolute Maasse, als das männliche hat, aber nicht durchgängig; namentlich findet sich das Umgekehrte bei den Thrïnenwerkzeugen und einzelnen Augenmuskeln.

Im Durchschnitt könne man sagen, dass das Auge zum Gewicht des ganzen Körpers ein günstigeres Verhältnis beim Mann habe. Ein männliches Auge wiegt nach Sö m mering 8200, ein weibliches $6600 \mathrm{mg}$, das männliche ist also um $1600 \mathrm{mg}$ schwerer. Das Verhältnis des Auges zum Körpergewicht wird beim Mann von Sömmering berechnet $=1: 5216$ bis $1: 10470$, beim Weib $=$ $1: 5816$ bis $1: 11621$, woraus ersichtlich ist, dass der weibliche Augapfel ein kleinerer Teil des Körpers ist, als der männliche.

Dieses Resultat erschien Sömmering selbst unerwartet, insofern das weibliche Auge so viele andere Eigenschaftes des kindlichen Auges teilt, ebenso wie der ganze Körper des Weibes so viel Ähnlichkeit mit dem kindlichen hat. Das ganze weibliche Auge ist aber grösser als das männliche im Verhältnis zum Gesicht und stimmt wenigstens hierin mit dem kindlichen Auge überein. Am weiblichen Auge, wird angegeben, sind die Häute zarter, die Hornhaut ist flacher und kleiner als die männliche.

Das Auge ist in seinem wesentliehen Bau schon vor der Geburt vollendet. Seine erste Entwickelung fällt in so frühe Zeit, dass nach der Geburt sich nur das Verhältnis seiner Teile ändert, aber kein eigentlich neues Organ entsteht. E's ist beim Embryo von so bedeutendem Umfang, dass sich auch für das Neugeborene und Kind gegen den Zustand des Wrwachsenen ein günstiges Grössenverhältnis erwarten lässt.

In der That sieht man dies sowohl am Volum, als Gewicht, die verhältnismässig zum Körper viel grösser sind, wie folgende Wägungen beweisen:

Bei einem neugeborenen Knaben von $1900 \mathrm{~g}$ wog der Augapfel $2200 \mathrm{mg}$ und stand also im Verhältniss wie 1:864 zum Körpergewicht, während dasselbe bis zu erwachsenem Alter zu $6^{1 / 2}-8^{1 / 2} \mathrm{~g}$ ausgewachsen ist, also nur um das 3 oder 4 fache, der Körper hingegen um das 30-40 fache, sein Wachstum also vom übrigen Körper um das 10 fache übertroffen wird und sich das Verhältnis in das von $1: 8549$ umwandelt.

Wie das Wachstum allmählich abnimmt, ersieht man an folgenden von dem Gewicht entnommenen Zahlen: Es wächst

$$
\begin{array}{ll}
\text { von der Geburt bis zu } 1^{1 / 2} \text { Jahren wie } & 1: 1,932, \\
\text { von da bis zum } 5 \text {. Jahre wie } & 1: 1,467, \\
\text { von da bis zum 12. Jahre wie } & 1: 1,105,
\end{array}
$$

von da bis zum erwachsenen Zustand

$$
\begin{aligned}
& \text { des Weibes wie } 1: 1,100 \text {, } \\
& \text { des Mannes wie } 1: 1,366 \text {. }
\end{aligned}
$$

, Hiernach würde es in den Pubertätsjahren wieder ein etwas besseres Wachstum erfahren als im Verlaufe der Kindheit, wo es immer langsamer zunimmt."

"Im höheren Alter nimmt Volum und Gewicht im allgemeinen ab." Mehr- 
mals wurden die Augen älterer Männer vom Gewicht des weiblichen Gesehlechts, nämlich $=6600 \mathrm{mg}$, gefunden.

Bei Ed. von Jäge ${ }^{1}$ ) finden sich über die Form und Wachstumsverhältnisse der kindlichen Augen folgende Angaben:

Die Augen Neugeborener zeigen im allgemeinen einen grossen Unterschied in ihren äusseren Durchmessern entsprechend der Verschiedenheit ihres Umfanges, da einzelne Kinder kleine, andere bedeutend grössere Bulbi besitzen; der Unterschied jedoch der einzelnen Durchmesser unter sich in demselben Auge ist bei weitem njcht so auffallend als wie bei Erwachsenen. Der Bau des Auges Neugeborener (überhaupt des Kindesauges) ist mehr gleichförmig. Dieser Bau bleibt gewöhnlich nur kurze Zeit unveründert, indem das Auge gleichzeitig mit den übrigen Organen sich mehr und mehr entwickelt, an Grösse besonders durch Entwickelung der hinteren Hemisphäre gewinnt. Die Entwickelung des Auges zu jener in späteren Lebensperioden charakteristischen, individuell abweichenden Form beginnt gewöhnlich mit dem vierten und fünften Lebensjahre und findet oft in den späteren Entwickelungsperioden des mensehlichen Körpers. im 12., 15. bis 18. Lebensjahr und später ihren völligen Abschluss."

„Bei dieser Ausbildung des Auges tritt gleich wie bei den übrigen Organen als wesentlich bestimmendes Moment vor allem die ursprüngliche Anlage hervor, wenn auch hier die Einwirkung verschiedener, auch äusserer Momente, besonders durch ihren Einfluss auf die Funktion des Sehorgans sich deatlich ausprägt. *

Nach Henle $\mathrm{e}^{2}$ ) schwankt das Gewicht des Bulbus zwisehen 6,3 und $8 \mathrm{~g}$. Das Volum beträgt etwa 1/3 Kubik-Zoll. Das Auge der Frau ist im allgemeinen, jedoch nicht ohne Ausnahme, kleiner als das des Mannes. Henle giebt an, dass Schneyder das Gewicht beider Bulbi bei einem fünf Monate alten Kinde zu 8,42 , bei einem 12 jährigen Knaben zu $15,86 \mathrm{~g}$ bestimmte.

Auch bei Hoffman $n^{3}$ ) findet sich die Angabe, dass das Auge der Frau um ein Unbedeutendes kleiner sei als dasjenige des Mannes. In betreff des Wachstums wird bemerkt, dass das Auge des Kindes von der Geburt bis zum ersten Jahr nicht unbeträchtlich wächst, dass es dann in den nächsten Lebensjabren nur wenig seine Grösse ändere, aber zur Zeit der Pubertät wieder mehr zunehme, und sich nun auf der alsdann erlangten Grösse erhalte.

Bei Merkel') findet man über die Wachstumsverhältnisse des Auges die Angabe, dass "Das kindliche Auge verhältnismässig sehr gross ist, Durehmesser nur wenig Millimeter geringer als beim Erwachsenen, auch

1) Über die Einstellung des dioptr. Apparates im menschlichen Auge. 1861.

־) Henle, Handb. d. Anatomie. 1866. Bd. II, pag. 586 u. 588.

3) Hoffmann, Lehrb. d. Anatomie. 1872. Bd. II, pag. 1384.

4) F. Merkel, Makrosk. Anatomie. Handbueh der ges. Augenleilkunde. Herausgegeb. von A. Gräfe u. Th. Sämisch. 1874. 
sind die verschiedenen Durchmesser einander ähnlicher, das jugendliche nähert sich also mehr der Kugelform (Jäger, Sappey).

„Das Volumen des Auges ändert sich bis zum 14.-15. Jahr nur wenig, dann bekommt es rasch seine definitive Grösse ${ }^{\star}$ (S a p pey).

"Was das Gewicht des Bulbus anlangt, so wird es von verschiedenen Beobachtern ziemlich gleichmässig angegeben. C. Krause findet ihn 6,2 bis 7,6 g schwer, Huschke giebt die Zahl 6,6-8,2 g, Henle 6,3-8,0, Sappey 7-8. Man wird also dem Mittelwert ziemlich nahe kommen, wenn man dafür die Zahl 7,0 annimmt. Sappey erwähnt noch, dass die beiden Augen eines und desselben Individuums um mehrere Gran differieren können. Es möchte jedoch hier die mehr oder minder reinliche Präparation ausschlaggebend sein."

Erwähnt wird auch noch, dass die Geschlechtsunterschiede im allgemeinen gering sind, das Auge der Frau ist kleiner als das des Mannes (Zin n u. a.).

R. Greeff $f^{t}$ ) citiert Fuchs, welcher angiebt, dass man auf den ersten Blick die Verschiedenheit zwischen dem Wachstum des ganzen Skeletts einerseits und des Gesichts-Skeletts andererseits erkennt. Das Wachstum des ganzen Körpers erfolgt im ersten Jahr rascher, dann langsamer bis zum 20. Lebensjahır, wo die volle Körpergrösse erreicht ist. Das Gesicht hingegen und speziell die Orbita wächst unverhältnismässig rasch in den ersten zwei Lebensjahren. Bei drejjährigen Kindern ist die Orbita nicht mehr viel kleiner als beim Erwachsenen.

Gre eff bestätigt dies, nur gilt nach ihm das, was von dem Wachstum der Orbita gesagt wird, genauer nur von dem des Orbitaeinganges. „Man kann sich leicht überzeugen und es ist überrasehend, dass, wenn man ein dreijähriges Kind neben die Mutter stellt, die Augen beider ungefähr ǵleich gross sind." Ganz anders gestaltet sich dies Verhältnis aber, wenn man die Äugen enukleieren würde. Das kindliche Auge in toto ist sodann bedeutend kleiner als das des Erwachsenen. Es findet also offenbar doch noch lange Zeit ein Wachstum des Auges statt, aber merkwürdigerweise nur nach hinten zu. Dieser Beobachtung entsprechen die Befunde an Schädeln. Der Orbitaeingang ist bei Kindern frühzeitig zu maximaler Grösse entwickelt und es findet von da ab noch ein bedentendes Wachstum der Augenböhle in die Tiefe statt. Das Kinderauge ist also ein anffallend grosses, weitgeöffnetes und rundes Auge. Die Grösse wird verursacht durch die Grösse der Hornhaut, die weite Öffnung und Rundung durch relative Kürze und die Elasticität der Lider.

In $\mathrm{H}$. Vierordts ${ }^{2}$ ) anatomischen Daten und Tabellen wird das Gewicht der beiden Augen beim Nengeborenen männl. $=9,0$ angegeben und

weibl. $=6,0$,

bei 22 jähriger Frau (nach $\mathbb{E}$. Bisch off) $=13,5$ (mit Sehnerv), bei 33 jährigem Mann " $"=12,5 \quad "$ " hei Mann zw. 30-45 Jhr. (nach G. v. Liebig) $=13,9$ bei Erwachsenen (nach Krause) $\quad=6,3-7,8$ (für ein Auge).

1) R. Greeff, Studien über die Plastik d. menschl. Auges d. Antike. Areh. f. Anat. 1892.

2) Herm. Vie rordt, Anatom. physiol. u. anatom. Daten und Tabellen zutm Gebrauche für Mediziner. Il. Aufl., 1893, S. 27 u. f. 
Als absolutes Gewicht der Augen des Neugeborenen wird pag. 29 angegeben 7,5 $\mathrm{g}$, beim Frwachsenen 13.7. Bezogen auf das Gesamtgewicht $(3,1$ beim Neugeborenen und $66,2 \mathrm{~K}$ beim Erwachsenen) beträgt

beim Neugeborenen das Gewicht der Augen 0,24\% des Gesamtgewichtes,

"Erwachsenen " " " " $0,02 \%$ ", "

Der männliche Gesamtkörper wiegt das 21 fache von dem des Neugeborenen, die Augen wachsen um das 1,8 fache.

Das Volumen des Auges wird $=6,6 \mathrm{~cm}$ angegeben (pag. 103).

Was meine eigenen Untersuchungen betrifft, so fand ich das Gewicht des Auges des Neugeborenen im Mittel von 14 Fällen $=2290$ Milligramm $($ Maximum $=2800$, Minimum $=1900)$; das Volum im Mittel $=2185($ Maximum $=2710$, Minimum $=1810)$.

Das Gewicht von 5 enmetropischen Augen Erwachsener betrug im Mittel: 7448 Milligramm (Maximum $=8250$, Minimum $=6720)$; das Volum im Mittel 7180 (Maximum $=7930$, Minimum $=6500$ ).

Von diesen 5 emmetropischen Augen waren 3 von Männern und 2 von Frauen. Von diesen beiden letzteren war das eine mit 8250 Milligramm das schwerste, das andere mit 6720 das leichteste.

Wie das Gewicht der Augen der Neugeborenen sehr verschieden gefunden wurde, so auch das Gewicht des emmetropischen Auges beim Erwachsenen. Letzteres kann nicht auffallend erscheinen, denn Grösse und Länge und dann auch das Gewicht des emmetropischen Auges können sehr verschieden sein ${ }^{1}$ ), Achsenlänge und optisches System müssen nur jeweils in der Relation zu einander stehen, dass parallel auffallende Strahlen auf der Netzhaut zu einem Bildpunkt vereinigt werden. Ein grosses Auge mit schwächerem optischen System und ein kurzes Auge mit stärkerem optischen System können beide emmetropisch sein.

1) Schnabel and Herrnheiser, Ühor Staphyloma postic., conus und Myopie. Zeitschr. f. Heilkunde, XVI. Bd. 1895. 
Tabelle I.

Zunahme des Gewichtes (resp. des Volums) des Auges bis zum ausgewachsenen Zustand.

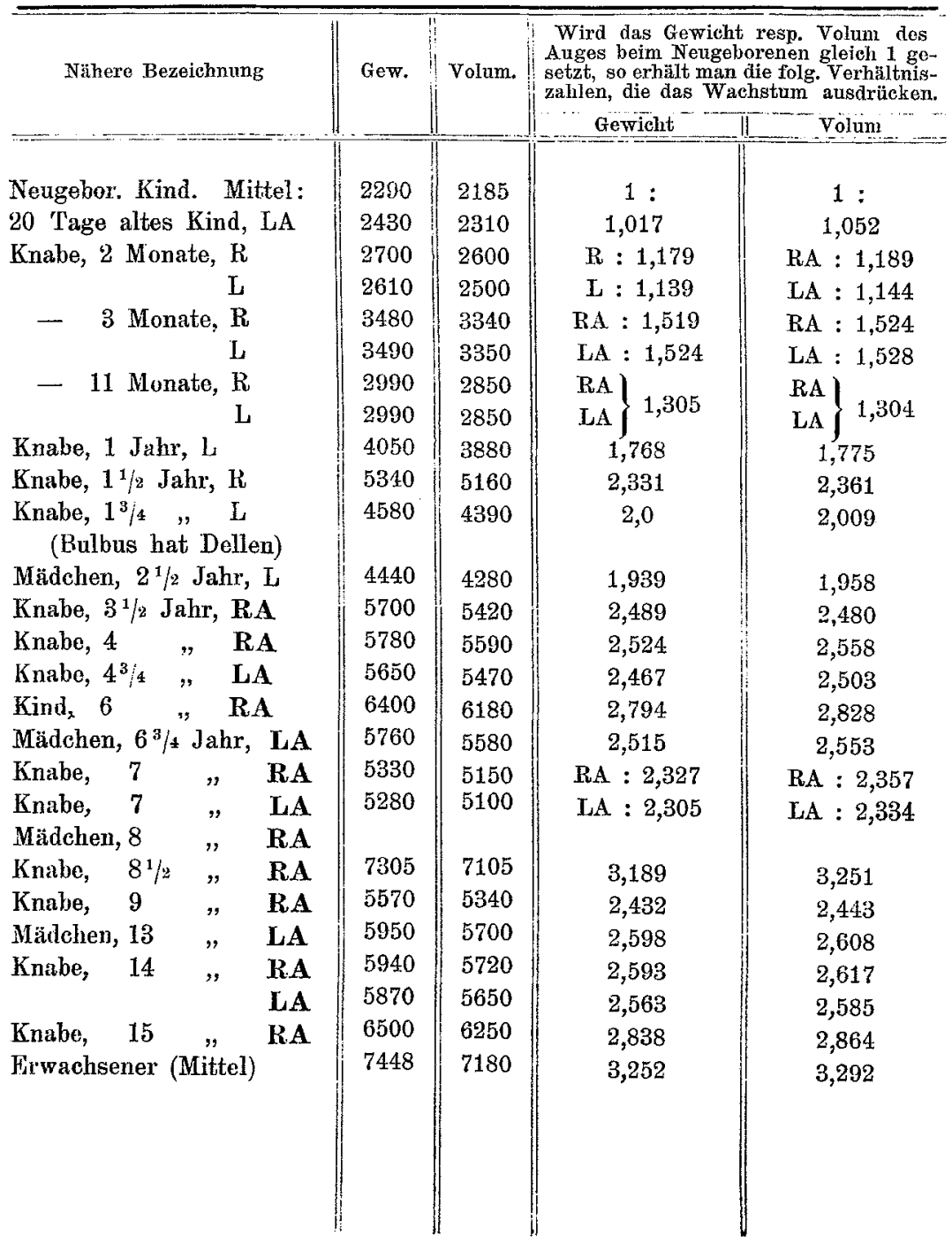


Tabelle II.

\section{Prozentarische Zunahme des Volums des Auges.}

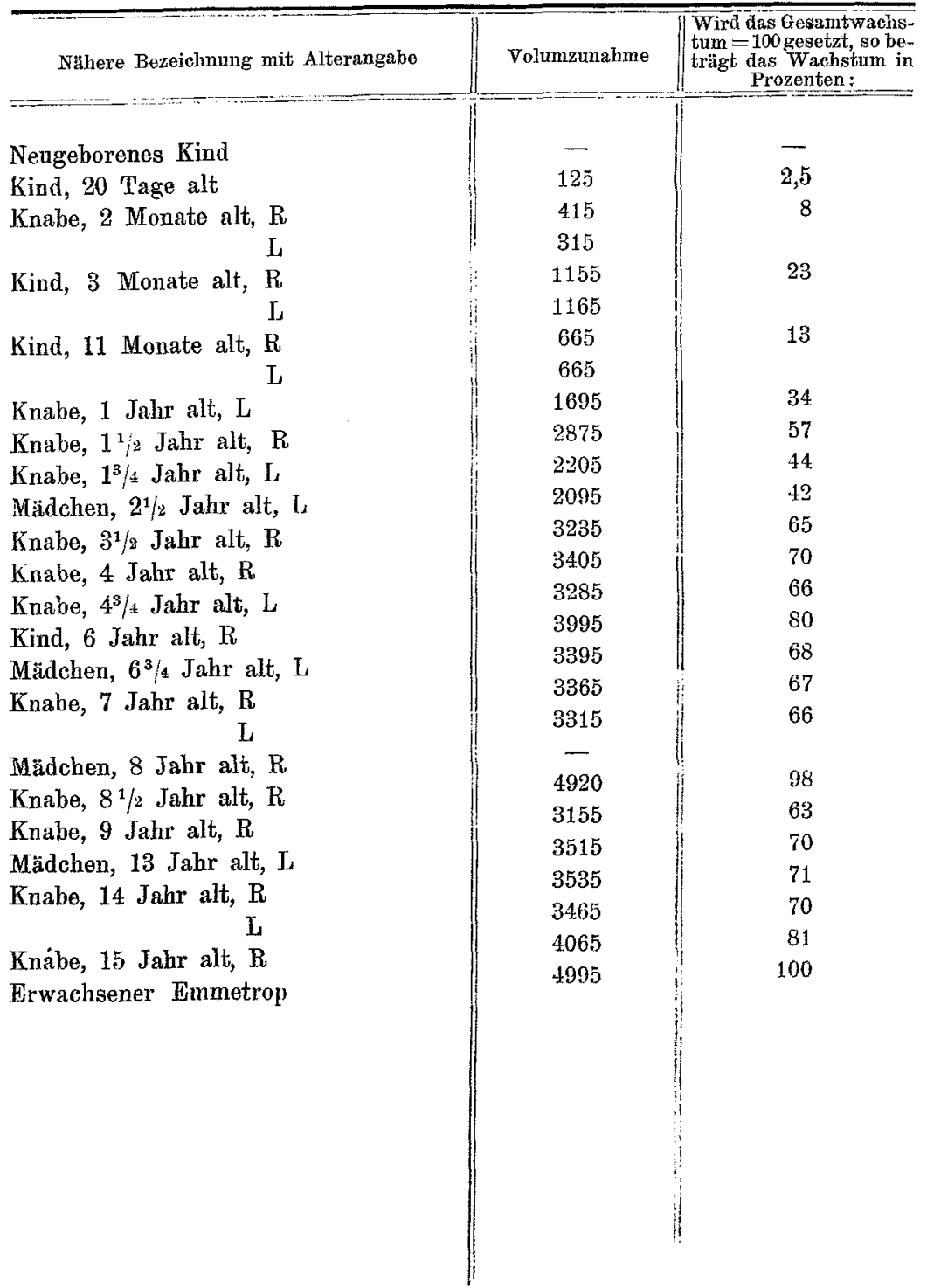


Seite 204.

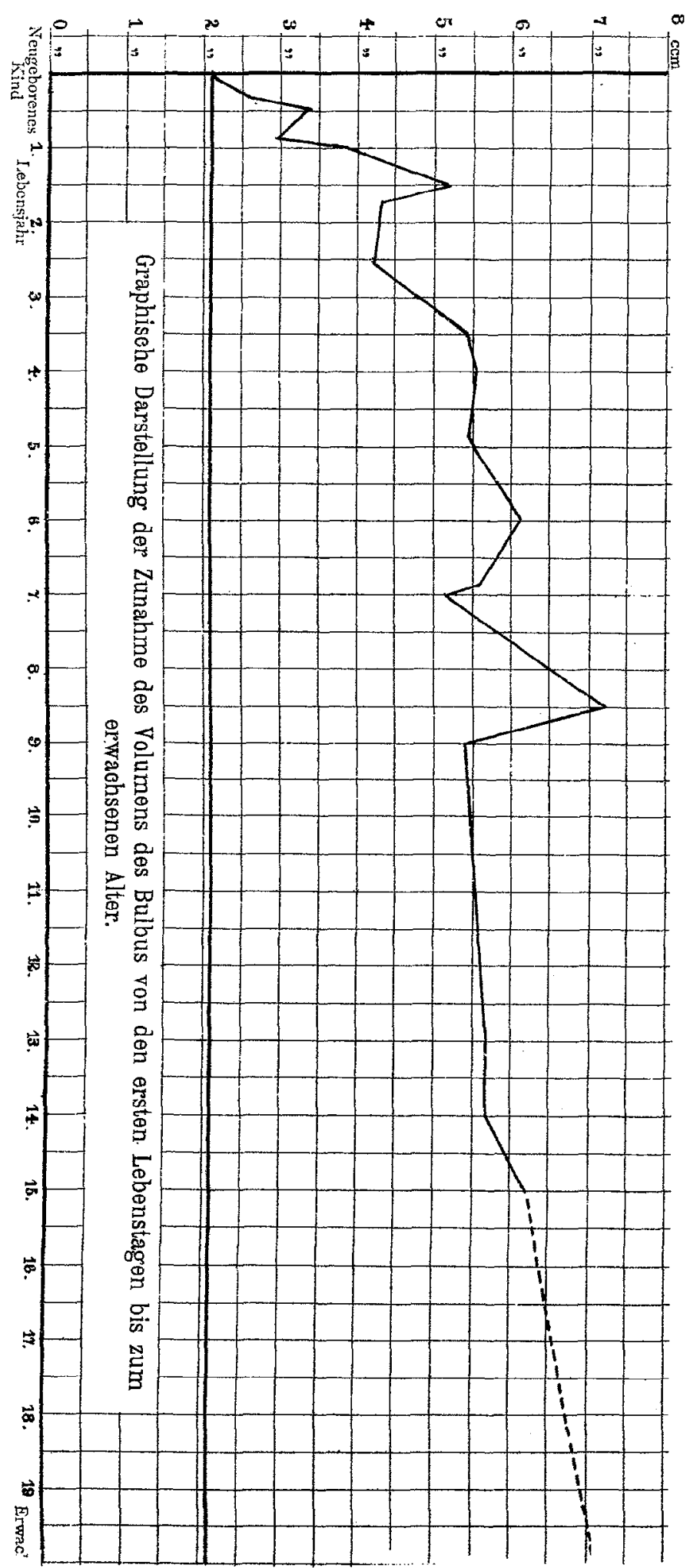


Tabelle III.

Das Wachstum des Auges im Vergleich mit dem Wachstum des Gehirns und des Gesamtkörpers (Maasse des Neugeborenen $=1,0$ ).

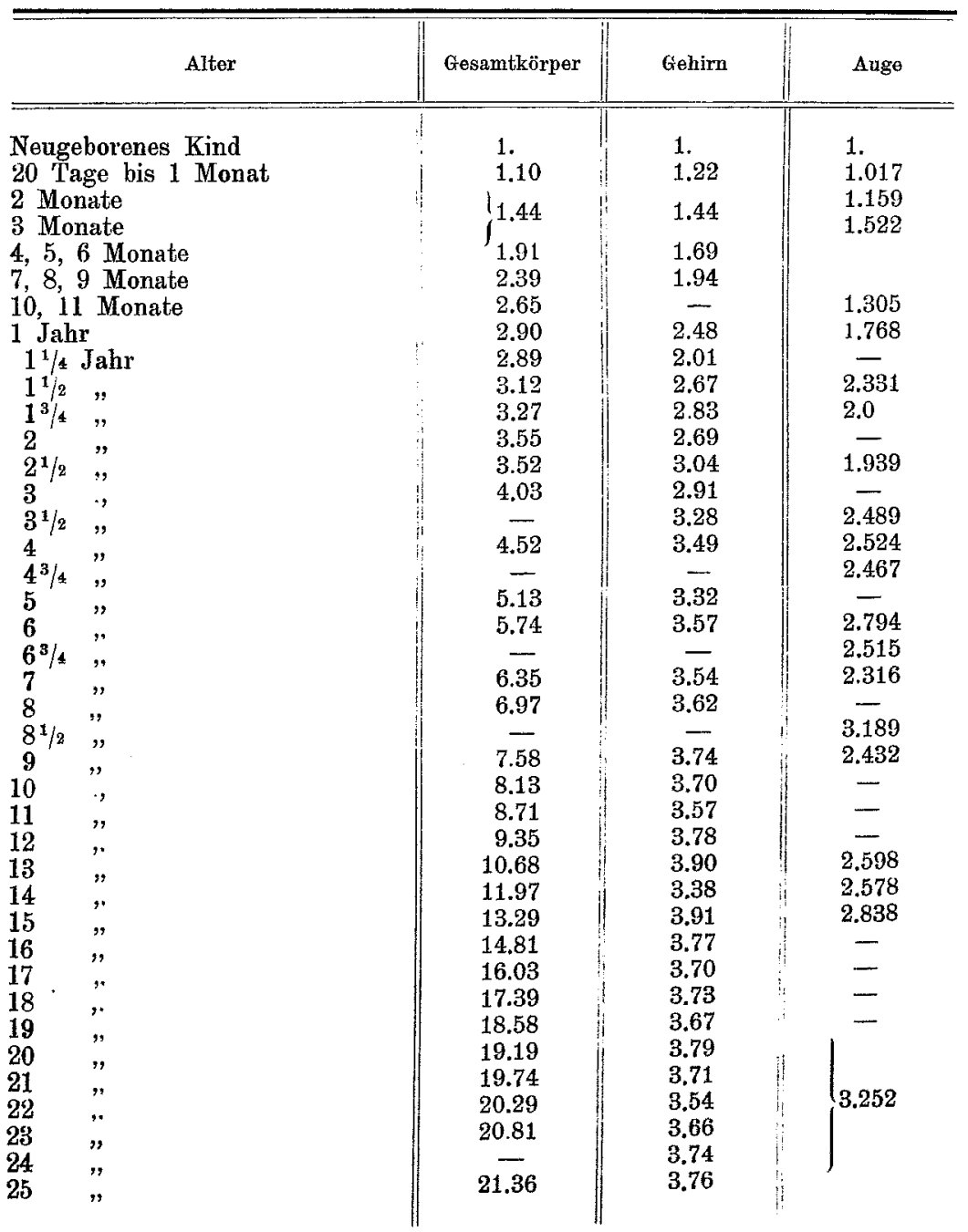

Zahlen für Körpergewicht und Gewicht des Gebirns nach Vierordt (Daten und Tabellen für Mediziner 1898. - Seite 24). 
Werden die bei neugeborenen und bei erwachsenen Emmetropen gefundenen Mittelwerte mit einander verglichen, so ergiebt dieser Vergleich, dass das Gewicht des Auges bis zum ausgewachsenen Zustand um das 3,252 fache und das Volum um das 3,292 fache zunimmt.

Inwiefern die von mir gefundenen Werte von früheren Angaben abweichen, geht aus den vorstehenden Litteraturangaben hervor.

Tabelle I zeigt, wie sich das Gesamtwachstum auf die einzelnen Lebensjahre verteilt. Es ist aus derselben ersichtlich, dass das rascheste Wachstum in den ersten Lebensjahren stattfindet, noch anschaulicher geht dies aus der Kurventafel I hervor, welche das Wachstum des Volums darstellt. Auf der horizontalen ist das Lebensalter aufgetragen und auf der vertikalen das Volum in Kubikmillimeter. Dass die Kurve vielfach Sprünge macht, auf und absteigend, kann nicht auffallend erscheinen, da die Zahl der untersuchten Fälle eine relativ kleine ist und individuell offenbar grosse Verschiedenheiten vorkommen. Sehr auffallend ist, dass bei einem $8^{1 / 2}$ jährigen Knaben das Volum $=7105$ war, somit beinahe dem Durchschnittswert beim Erwachsenen gleichkam, es war mir in diesem Fall bei der Sektion gleich aufgefallen, dass der Knabe, der an Sarkom des Oberschenkels litt, für sein Alter ganz aussergewöhnlich stark entwickelt war.

In Tabelle II ist die prozentarische Zunahme des Volums des Auges in den verschiedenen Lebensjahren angegeben.

Wie bekannt, wächst das Gewicht des Gesamtkörpers etwa um das 21 fache, das Gesamtwachstum des Auges betrug nach meinen Untersuchungen nur das 3,252 fache. Sehr auffallend ist die Ähnlichkeit des Wachstums des Auges mit dem des Gehirns, das nach Vierordt um das 3,76 fache zunimmt. Diese Ähnlichkeit ist noch auffallender, wenn man das Wachs- 
tum beider in den verschiedenen Lebensabschnitten mit einander vergleicht; beide zeigen annähernd parallel gehend das rascheste Wachstum in den ersten Lebensjahren. Aus Tabelle III und Kurventafel II (cf. Taf. XXXI) ist ersichtlich, in welcher Weise bei beiden sich das Gesamtwachstum auf die einzelnen Lebensjahre verteilt. Auf Kurventafel II stellt die punktierte Kurve das Wachstum des Auges, die ausgezogene Linie das Wachstum des Gehirns dar. Der Abschluss für das Wachstum des Gesamtkörpers wird gewöhnlich in das 25. Lebensjahr verlegt, das Wachstum von Auge und Gelirn dürfte meist schon früher beendigt sein. Wegen der vorkommenden vielen individuellen Verschiedenheiten bietet die Feststellung der Wachstumsgrenze des Auges nicht unerhebliche Schwierigkeiten. Nur durch sehr umfangreiche Untersuchungen lässt sich diese Frage der Lösung zuführen.

Mit Rücksicht auf den innigen genetischen Zusammenhang, der zwischen Gehirn und Auge besteht, ersclieint das ziemlich parallel gehende Wachstum beider von ganz besonderer Bedeutung. Trotzdem dass an dem entwickelten Auge der von der primären Augenblase abstammende Teil verhältnismässig nur gering ist, scheint dieser, wenn auch kleine, so doch physiologisch wichtigste Teil von ausschlaggebender Bedeutung für das Wachstum des gesamten Organs zu sein.

\section{Durehmesser und Umfang des Auges.}

Nachdem das Gesamtwachstum des Auges von der Gelurt an bis zum ausgewachsenen Zustande festgestellt war und nachdem ermittelt worden, wie sich das Gesamtwachstum auf die einzelnen Lebensjahre verteilt, blieb noch zu untersuchen, wio die einzelnen Durchmesser des Auges während des Lebens zu. 
nehmen, insbesondere war zu untersuchen, ob die verschiedenen Durchmesser gleichmässig wachsen, so dass die bei der Geburt bestehende mitgebrachte Form des Auges während des Lebens erhalten bleibt, - oder ob die verschiedenen Durchmesser des Auges ungleichmässig wachsen und die definitive Form des normalen emmetrop. Auges des Erwachsenen sich erst im Laufe des Lebens herausbildet.

Von verschiedenen Seiten wird hervorgehoben, dass letzteres der Fall sei. Das Auge des Neugeborenen und auch das des Kindes soll mehr rundlich sein, die verschiedenen Durchmesser sollen einander ähnlicher sein als beim Auge des Erwachsenen. Ehe das Ergebnis meiner Untersuchungen mitgeteilt wird, sei es gestattet, eine kurze Zusammenstellung der Angaben über die Durchmesser des wachsenden und ausgewachsenen Auges zu geben, die man in den Lehrbüchern findet.

Ausführliche Angaben über Form und Durchmesser des Auges finden sich, wie oben schon angeben, bei Sö $\mathrm{m} \operatorname{mer} \operatorname{ing}^{1}{ }^{1}$ ). Es heisst daselbst pag. 653:

„Der Augapfel ist von vorn nach hinten etwas zusammengedrückt, was im Einklang mit der Wirkung der geraden Augenmuskeln steht, und zweitens schief von aussen oben nach unten innen kürzer und komprimiert. Die Grösse der verschiedenen Durehmesser entspricht im allgemeinen auch den gleichen Durchmessern der Augenhöhle, die ansehnlichsten Durchmesser liegen daher diagonal, d. h. mit ihren Endpunkten in den Zwischenräumen der geraden Augenmuskeln. Der äussere kleine Diagonaldurchmesser liegt vom Zwischenraum des inusseren und oberen zum Zwischenraum des inneren und unteren geraden Augenmuskels und ist meistens um ${ }^{1 / 10}-3 / 10^{\prime \prime \prime}$ länger als die Augenachse." Der innere grosse Diagonal-Durchmesser liegt ungefähr senkrecht auf dem äusseren kleinen und hat eine Länge von 11-11 $1 / 3^{\prime \prime}$, ist also der längste von allen, selbst die Augenachse nicht ausgenommen. Der senkrechte Durchmesser ist der äusseren Augenachse meistens gleich oder um $1 / 10-1 / 3$ " kürzer. Der änssere Querdurchmesser ist der Achse beinahe gleich."

Bei den Angaben, welehe von $S 00 \mathrm{mmering}$ über die Länge der Augenachsen gemacht werden, ist zu beachten, dass die von Sö mmering angegebenen Masse sich bald auf die Sehachse, bald anf die Sehnervachsen be-

1) 1. c. 
ziehen. Achsen nennt Sömmering die Durchmesser von vorn nach hinten; „es sind ihrer zwei, die Sehachse und die Sehnervenachse. Die Sehachse oder Augenachse teilt man in eine äussere und eine innere. Die äussere Achse ist die gerade linie, welche von der Mitte der vorderen Hornhautfläche zum Mittelpunkt der hinteren Wölbung der Sclerotica (innerlich durch den gelben Fleck der Netzhaut) gezogen wird. Sie ist die optische Achse and ihre Länge beträgt 10,2-11"', häufiger aber unter $11^{\prime \prime \prime}$ nach $\mathrm{K}$ a a se (nach anderen selbst $11 / \mathrm{s}^{\prime \prime \prime}$ schon bis zur Netzhaut, so dass sie dann mit der Dicke der Häute auf 1 Zoll steigen würde)“. „Die innere Sehachse erstreckt sich von der Mitte der hinteren Fläche der Hornhaut bis zum Mittelpunkt der Vorderfläche der Netzhaut und beträgt $9-9,9^{\prime \prime \prime}$, nach K raus e $9^{3} / 4$ bis $10^{\prime \prime \prime}$.

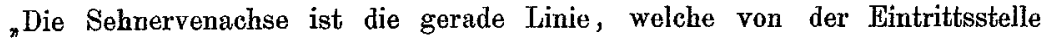
des Sehnerven in die Sclerotica, also 1-1,2" nach innen vom hinteren Ende der Augenachse nach der Mitte, oder nach Kra use nach dem änsseren Drittel der Hornhaut gezogen wird. Nach Krause schneidet sie sich mit der Sehachse unter einem Winkel von $20^{\circ} . "$ S. 790 giebt Sö mmering eine Zusammenstellung der Durchmesser des Auges, die bei 13 Erwachsenen im Alter von 21-60 Jahren gefunden wurden.

Die äussere Achse betrug im Mittel: 10,56" Max. 11,05“", Min. 9,7“",

Der quere Durchmesser betrug im Mittel: $\quad 10,56^{\prime \prime \prime}$ Max. 11,9"', Min. 9,5"'.

n senkrechteäuss.Durchm. betrug im Mittel: 10,433"“ Max. 10,8"', Min. 10,0"'.

In Betreff des Verhaltens der Durchmesser am wachsenden Auge wird angegeben, dass bei einem 6jährigen Knaben von Home Querdurchmesser, Sehnervenachse und Sehachse untereinander völlig gleich, nämlich $\frac{17 \frac{1}{2}}{20}$ Zoll gefunden wurden. Beim 20 jührigen Jüngling waren Querdurchmesser und Sehnervenachse gleich und betrugen $\frac{17^{3} / 4}{20}$, während die Sehachse etwas kleiner, nämlich $=\frac{17}{20^{\prime \prime}}$ gefunden wurde.

Es wird angenommen, dass Querdurchmesser und Sehnervenachse vom 6. bis 50. Jahre gleich bleiben, dagegen die Sehachse abnimmt. „Beim Greis findet man diese Achse regelmüssig kürzer. ${ }^{*}$ Nach $\mathrm{Krause}$ verhalten sich Achse und Durchmesser beim Neugeborenen zu denen des Krwachsenen ziemlich wie 7:9. Die Diagonalen unterscheiden sich noch nicht so merklich vom Querdurchmesser, obgleich auch hier die grosse Diagonale um 0,02 bis $0,03^{\prime \prime \prime}$ linger zu sein pflegt, als die Achse." Ferner wird angegeben, dass die äussere Augenachse und der Querdurchmesser bei einem dreiwöchentlichen Kinde gleich $8^{1}{ }_{i} 3^{\prime \prime \prime}$, die Sehnervenachse gleich $8^{\prime \prime \prime}$, bei einem $1^{1 / 2}$ jährigen Kinde die Sehachse gleich $9^{1 / 2} \mathbf{2}^{\prime \prime}$ gefunden wurde ${ }^{1}$ ).

Bei Holstein ${ }^{2}$ ) wird angegeben, dass der Augapfel ungefähr 1 "im Durchmesser hat und dass das Grössenverhältuis der einzelnen Durehmesser nicht

1) 1. c. S. 187.

2) Holstein, Anatomie des Menschen. 1852, S. 186 , 


$\begin{array}{cccc} & \begin{array}{c}\text { Die äussere } \\ \text { Augenaxe, }\end{array} & \begin{array}{c}\text { der } \\ \text { transversale }\end{array} & \begin{array}{c}\text { und der vertikale } \\ \text { Querdurchmesser }\end{array} \\ \text { wurden gefunden von Petit } & 24,7 & 24,1 & 24,1 \\ \text { von D. W. Sömmering } & 22,5 & 21,3 & 21,3 \\ \text { "Tiedemann } & 23,6 & 22,2 & 22,2 \\ \text { " Treviranus } & 23,4 & 24,7 & 24,7 \\ \text { " Huschke } & 22,5 & 22,5 & 22,0 \\ \text { " Krause } & 24,1 & 24,1 & 23,7 \\ \text { " Brücke } & 24,5 & 24,9 & 24,4 \\ \text { " Sappey } & 24,3 & 23,6 & 23,2 \\ \text { " Jäger } & 24,3 & 23,6 & 23,4 \\ \text { " Volkmann } & 24,7 & 24,2 & - \\ \text { " Henle } & 24,0 & 23,5 & 23,1 \\ \text { " F. Merkel } & & & \\ \text { schemat. Ange } & 24,3 & 23,6 & -\end{array}$

Ferner sei aus der Zusammenstellung noch erwähnt, dass Jurin die Augenachse $=27$, Arlt $=24$, Rü te $=24,5$ und Listing $=24,2$ angiebt.

Was die Wachstumsverhältnisse des Auges betrifft, so findet sjch daselbst - wie oben schon angegeben worden ist - die Bemerkung, dass das kindliche Auge verhältnismässig gross sei, dass seine Durchmesser nur wenige Millimeter geringer sind als beim Erwachsenen, auch seien die verschiedenen Durchmesser beim Kind einander ähnlicher, der jugendliche Bulbus nähere sich daher mehr der Kugelform. Nach $\mathrm{H}$ ome waren bei einem 6jährigen Knaben sämtliche Durchmesser $=21,14$.

Flem ming ${ }^{1}$ ) giebt die äussere Augenachse $=24$, die innere $=23 \mathrm{~mm}$ an, den grössten horizontalen Durchmesser im Äquator $=24,3$.

In dem Handbuch der topographischen Anatomie führt Merkel ${ }^{2}$ ) im wesentlichen dieselben Maasse für die Durchmesser des Auges auf, wie im Handbuch der gesammten Augenheilkunde von Gräfe-Sämisch.

Bei $V$ i eror $d t^{3}$ ) wird die äussere Augenachse $=24$, die innere $=23 \mathrm{~mm}$ angegeben, der grösste horizontale Durchmesser des Bulbus im Aquator = 24,3 , der schräge Durchmesser $=24$. Äquatorialer Umfang des Bulbus nach Merkel $=72,2$.

Was meine Messungen betrifft, so wurden beim Neugeborenen die Durchmesser im Mittel von 14 Fällen gefunden vertikal : 15,4 (Max. 17,0, Min. 14,5), horizontal : 16,0 (Max. 17,75, Min. 14,5), sagittal : 16,4 (Max. 17,5, Min. 15,75).

1) Flemming, Text zur Karte des menschl. Auges. 1887. S. 8.

2) Handb. d. topograph. Anatomie von F. Merkel. 1891.

3) Anatom. physiol. u. physikal. Daten und Tabellen von H. Vierorilf. II. Aufl. 1893 . 
Fast ausnahmslos war die Reihenfolge die angegebene, der vertikale Durchmesser war der kleinste, der sagittale der grösste, nur bei zwei Augen war der horizontale ein wenig grösser als der sagittale, in allen Fällen war der vertikale Durchmesser der kleinste.

Wird die Grösse des vertikalen Durchmessers $=1$ gesetzt, so verhalten sich beim Neugeborenen der vertikale, horizontale und sagittale Durchmesser wie $1,0: 1,04: 1,065$.

Bei dem Erwachsenen wurden die Durchmesser im Mittel gefunden:

vertikal $=23,70 \quad$ In allen Fällen war der horizontale Durchhorizontal $=24,43 \quad$ messer am grössten, in 3 Fällen waren vertisagittal $=23,85$ kaler und sagittaler Durchmesser gleich.

Die Grösse des vertikalen Durchmessers $=1$ gesetzt, verhalten sich vertikal. : horizont. : sagittal. Durchmesser wie $1,0: 1,03: 1,006$.

Vergleicht man die entsprechenden Durchmesser des Auges vom Neugeborenen und Erwachsenen mit einander, so wächst der vertikale Durchmesser im Verhältnis $1: 1,, 539$,

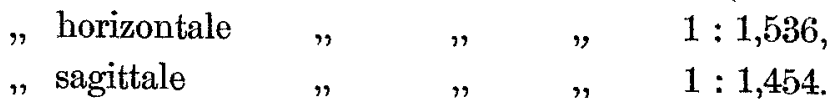

Während der vertikale und horizontale Durchmesser ungefähr in gleichem Verhältnis wachsen, bleibt das Wachstum des sagittalen diesen beiden gegenüber etwas zurück.

Was die bei verschiedenen Autoren zu findende Angabe betrifft, das kindliche Auge nähere sich mehr der Kugelform, seine einzelnen Durchmesser seien einander ähnlicher, so ergeben meine Messungen durchaus keine Bestätigung hierfür, wenigstens nicht für das Auge des Neugeborenen; im Gegenteil geht aus denselben hervor, dass, wenn auch die absoluten Masse der einzelnen Durchmesser bei der Kleinheit des Auges um geringere Werte differieren, - die relativen Differenzen zwischen den 
einzelnen Durchmessern beim Neugeborenen grösser sind als beim Erwachsenen.

Wenn Krause angiebt, die Durchmesser des Auges vom Neugeborenen und Erwachsenen verhielten sich wie $7: 9$, so geht aus den mitgeteilten Messungswerten hervor, dass

der Sagittal-Durchmesser wächst im Verhältnis von $7: 10,19$,

"Horizontal- " " " " $, 7: 10,69$,

"Vertikal- " " , " " , $7: 10,76$,

In Tabelle IV sind die Messungswerte der Durchmesser von kindlichen Bulbis verschiedenen Lebensalters zusammengestellt; in jedem einzelnen Fall ist das Wachstumsverhältnis der drei Durchmesser angegeben, bezogen auf die Grösse des betr. Durchmessers beim Neugeborenen, wenn dessen Grösse $=1$ gesetzt wurde.

Aus dieser Zusammenstellung ist ersichtlich, dass im Allgemeinen der vertikale Durchmesser am raschesten wächst, der sagittale am langsamsten. Indem der bei der Geburt kleinste Durchmesser, (der vertikale) am raschesten wächst, der bei der Geburt grösste sagittale dagegen das langsamste Wachstum hat, kann es nicht auffallend erscheinen, dass an kindlichen Augen die Durchmesser unter einander ähnlicher gefunden werden, wodurch dasselbe eine mehr kugliche Form gewinnt; es gilt dies für kindlicbe Augen bis etwa zum neunten Lebensjahr, hier war die grösste Differenz der Durchmesser unter einander bei 10 Augen nur $0,5 \mathrm{~mm}$, bei 2 Augen betrug sie nur 0,2 resp. 0,3 und bei einem sechsjährigen waren sagittaler, horizontaler und vertikaler Durchmesser einander völlig gleich und hatten eine Länge von je $21,3 \mathrm{~mm}$. Bei älteren Kindern treten wieder grössere Differenzen hervor und zwar meist im Sinne der definitiven Form des Auges, bei welcher der horizontale Durchmesser den sagittalen übertrifft bezw. demselben gleichkommt, während der vertikale trotz des stetigen stärkeren Wachstums hinter den beiden anderen etwas zurückbleibt, was sich dadurch erklärt, 
Tabelle IV.

\begin{tabular}{|c|c|c|c|c|c|c|}
\hline & \multicolumn{3}{|c|}{ Durchmesser des Bulbus } & \multicolumn{3}{|c|}{$\begin{array}{l}\text { Durchmesser-Verhältmis- } \\
\text { zahlen (Durehmesser des } \\
\text { Neugeborenen }=1.0 \text { ) }\end{array}$} \\
\hline & sagittal & horizont. & vertikal & sagittal & horizont. & vertikal \\
\hline Neugeborenes Kind (Mittel) & 16.40 & 16.0 & 15.40 & 1.0 & 1.0 & 1.0 \\
\hline Kind, 20 Tage alt & 16.75 & 16.75 & 16.0 & 1.021 & 1.046 & 1039 \\
\hline Knabe, 2 Monate alt, RA & 17.0 & 16.5 & 17.0 & 1.036 & 1.031 & 1.103 \\
\hline LA & 17.0 & 16.5 & 17.0 & 1.036 & 1.031 & 1.1 .03 \\
\hline Kind, 3 Monate, RA & 18.5 & 19.0 & 18.5 & 1.128 & 1.187 & 1.201 \\
\hline $\mathrm{LA}$ & 18.0 & 19.0 & 18.0 & 1.097 & 1.187 & 1.168 \\
\hline Mädchen, $3^{1 / 2}$ Monat, RA & 19.0 & 19.0 & - & 1.158 & 1.187 & - \\
\hline 1.A & 19.0 & - & 19.0 & 1.158 & - & 1.233 \\
\hline Mädchen, $3^{1} / 2$ Monat, LA & 18.0 & - & - & 1.097 & - & - \\
\hline Kind, 11 Monat, LA & 17.5 & 18.0 & 18.0 & 1.067 & 1.125 & 1.168 \\
\hline RA & 17.5 & 18.0 & 18.0 & 1.067 & 1.125 & 1.168 \\
\hline Knabe, 1 Jahr, LA & 18.3 & 20.0 & 19.75 & 1.115 & 1.250 & 1.282 \\
\hline Knabe, $1^{1 / 2}$ Jahr, RA & 21.5 & 21.0 & 21.0 & 1.310 & 1.312 & 1.363 \\
\hline Knabe, $1^{3} / 4$ Jahr, LA & 20.0 & 20.5 & 20.0 & 1.219 & 1281 & 1.298 \\
\hline Mädchen, $2^{1 / 2}$ Jahr, LA & 19.0 & 20.0 & 20.0 & 1.158 & 1.250 & 1.298 \\
\hline Knabe, $3^{1 / 2}$ Jahr, RA & 21.5 & 21.0 & 22.0 & 1.310 & 1.312 & 1.428 \\
\hline Knabe, 4 Jahr, RA & 21.0 & 21.3 & 21.3 & 1.280 & 1.331 & 1.383 \\
\hline Knabe, $4 x^{3} / 4$ Jahr, LA & 21.0 & 22.0 & 21.3 & 1.280 & 1.375 & 1.383 \\
\hline Kind, $6 \mathrm{Jahr}, \mathrm{RA}$ & 21.3 & 21.3 & 21.3 & 1.291 & 1.331 & 1.383 \\
\hline Mädchen, $6^{3} / 4 \mathrm{Jahr}, \mathrm{LA}$ & 20.5 & 21.0 & 20.75 & 1250 & 1.312 & 1.347 \\
\hline Knabe, 7 Jahr, RA & 21.5 & 21.25 & 21.0 & 1.310 & 1.328 & 1.363 \\
\hline Knabe, $7 \mathrm{Jahr}$, LA & 20.5 & 20.0 & 20.3 & 1.250 & 1.281 & 1.318 \\
\hline Knabe, 7 Jahr, RA & 23.0 & 23.0 & - & 1.402 & 1.437 & - \\
\hline LA & 22.5 & 24.0 & - & 1.372 & 1.50 & - \\
\hline Mädchen, 8 Jahr, RA & 21.0 & 21.5 & 21.3 & 1.280 & 1.343 & 1.383 \\
\hline Knabe, 81/2 Jahr, RA & $23 . \tilde{5}$ & 24.0 & 24.5 & 1.432 & 1.5 & 1.591 \\
\hline Knabe, 9 Jahr, RA & 20.75 & 20.5 & 20.25 & 1.265 & 1.281 & 1.314 \\
\hline Mädchen, 13 Jahr, LA & 21.75 & 21.75 & 20.75 & 1.326 & 1.359 & 1.347 \\
\hline Knabe, 14 Jahr, RA & 20.0 & 22.0 & 23.0 & 1.219 & 1.375 & 1.493 \\
\hline LA & 21.0 & 22.5 & 22.3 & 1.280 & 1.406 & 1.448 \\
\hline Knabe, 15 Jahr, RA & 22.3 & 21.5 & 22.0 & 1.359 & 1.343 & 1.428 \\
\hline $\begin{array}{l}\text { Erwachsenes, emmetr. Auge } \\
\text { (Mittel) }\end{array}$ & 23.85 & 24.43 & 23.70 & 1.454 & 1.536 & 1.539 \\
\hline
\end{tabular}




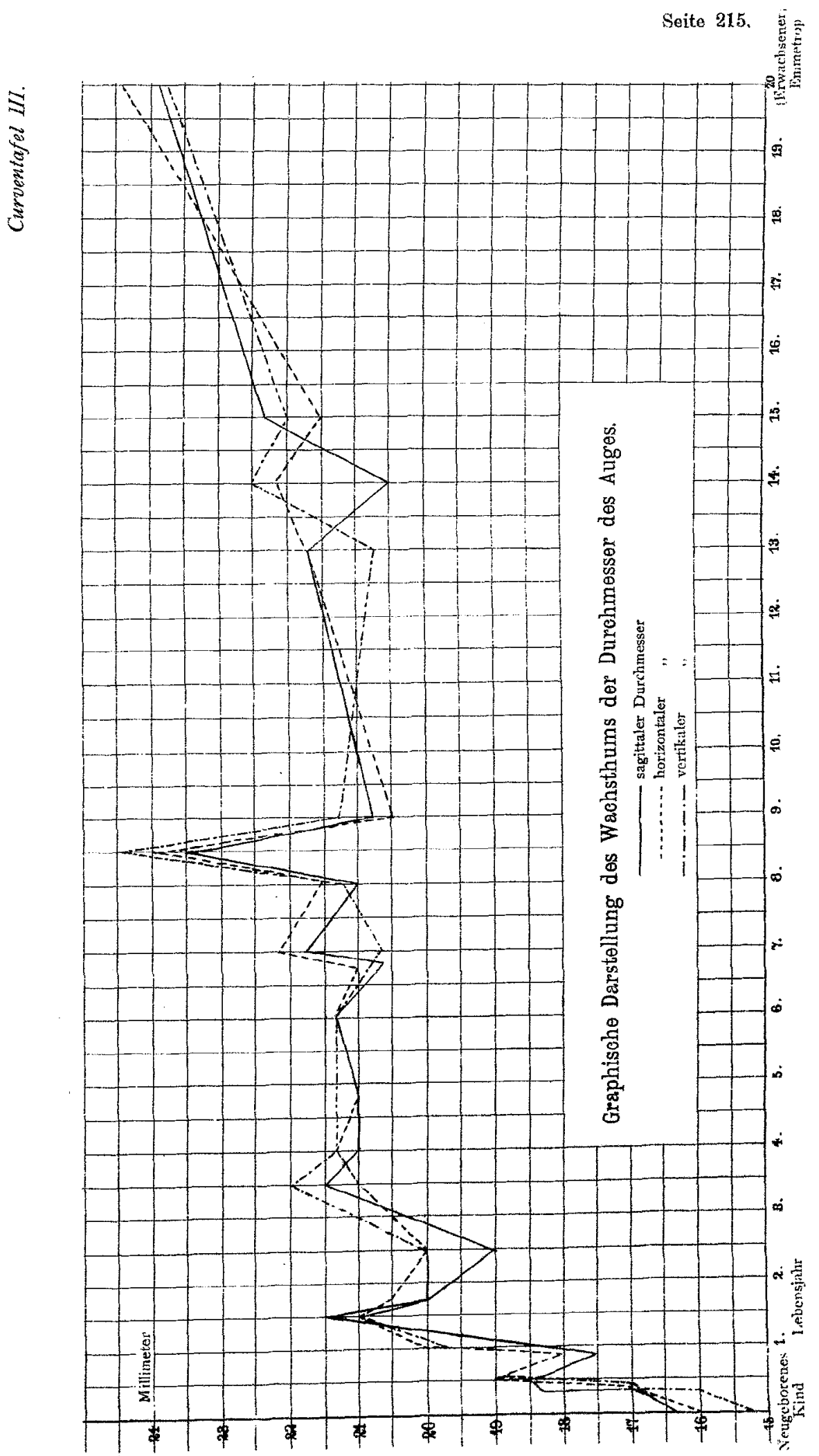


dass eben der vertikale Durchmesser bei der Geburt erheblich kleiner ist als der sagittale.

Auf Kurventafel III (pag. 215) ist graphisch das Wachstum der einzelnen Durchmesser dargestellt.

Der Umfang des Auges wurde beim Neugeborenen im Mittel sagittal: $=51,2 \quad($ Max. 54,6, Min. 46,7 $)$,

horizontal: $=52,96($ Max. 57,0, Min. 49),

äquatorial: $=51,6$ (Max. 56,3, Min. 48) gefunden.

Wird die Grösse des sagittalen Meridians gleich 1 geset\%t, so verhalten sich

$$
\begin{array}{ccccc}
\text { sagittal } & \text { : } & \text { horizontal } & \text { : Äquatorialumfang } \\
\text { wie } 1 & : & 1,033: & 1,008
\end{array}
$$

Bei dem emmetropischen Auge des Erwachsenen wurde im Mittel der Umfang

$$
\begin{aligned}
& \text { sagittal }=76,2(\operatorname{Max} .79,0, \text { Min. 73,75), } \\
& \text { horizontal }=76,85(\text { Max. 79,0, Min. 73,75), } \\
& \text { äquatorial }=77,62(\operatorname{Max} .81,0, \text { Min. 75,25). }
\end{aligned}
$$

Wird die Grösse des sagittalen Umfangs hier gleich 1 gesetzt, so verhalten sich

$$
\begin{array}{rlccc}
\text { sagittal } & \text { : horizontal } & \text { : Äquatorialumfang } \\
\text { wie } 1 & : & 1,0085 & : & 1,02
\end{array}
$$

Vergleicht man den entsprechenden Umfang beim Auge des Neugeborenen mit dem beim Erwachsenen, so ergiebt sich für den sagittalen Umfang eine Zunahme im Verhältnis von $1: 1,488$, horizontalen

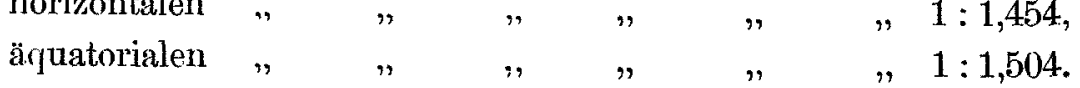

Berechnet man aus den entsprechenden Durchmessern unter der Annahme, dass der betreffende Umfang einer Ellipse entspricht, die Grösse des Umfangs des Auges, so erhält man etwas kleinere Werte als sie durch direkte Messung gefunden wurden, so berechnet sich der äquatoriale Umfang beim Neugeborenen $=49,3$, beim Erwachsenen $=75,55$. Die Differenz zwischen berech- 
Tabelle V.

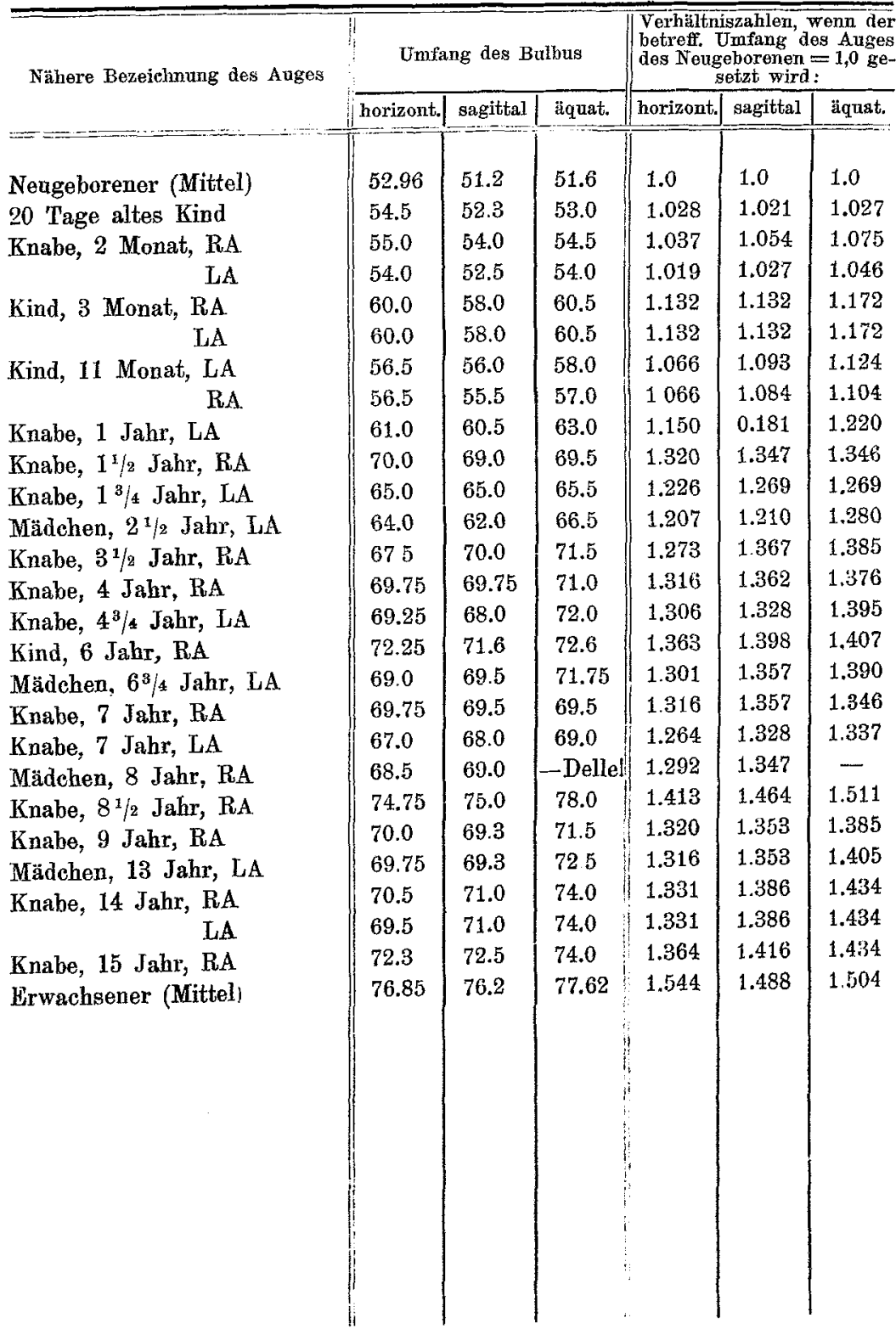


netem und gemessenem Wert dürfte sich einmal dadurch erklären, dass die gemachte Ammahme, der betreffende Umfang entspreche einer regelmässigen Ellipse, nicht ganz zutreffend ist, und dann ferner aus kleinen nicht ganz zu vermeidenden Messungsfehlern.

Die von Merkel für den Äquatorialumfang angegebene Zahl 72,2 ist entschieden zu klein. Sie berechnet sich unter der nicht berechtigten Annahme, dass der Äquatorumfang einen Kreis darstellt, dessen Radius ${ }^{23 / 2}$ ist, nach der Formel $2 \mathrm{r} \pi$ $=23 . \pi=72,2$.

Aus Tabelle $\mathrm{V}$ ist ersichtlich, wie der Umfang in den verschiedenen Lebensjahren zunimmet; beigefügt ist, in welchem Verhältnis die betreffenden Werte zunehmen, wenn der Wert des entsprechenden Umfangs beim Neugeborenen $=1$ gesetzt wird.

Wie schon oben angegeben wurde, wurden von sämtlichen Augen mit Hilfe des Lucäschen Zeichenapparats genaue Aufzeichnungen ihrer Form und der Muskelinsertionen gemacht und zwar sowohl von oben und unten, als auch von der temporalen und der nasalen Seite. Eine Anzahl solcher Zeichnungen lässt am anschaulichsten die Veränderungen am wachsenden Auge erkennen (vgl. Tafel XXXII/XXXIII).

\section{Das Verhalten der Muskelinsertionen.}

Es erübrigt noch etwas näher auf das Verhalten der MuskeIinsertionen am wachsenden und am ausgewachsenen Auge einzugehen.

Bei den diesbezüglichen Untersuchungen wurde gemessen:

1. die Breite der Insertionen,

2. der Abstand der Mitte der Insertion der recti vom Hornhautrande, 
3. der betr. Abstand vom Sehnervenumfang,

4. der Abstand der beiden Endpunkte der Insertion der recti vom Hornhautrande. Aus den hier gefundenen Messungswerten wurde die Schrägstellung der Insertionen berechnet. Fermer wurde noch das Verhalten der obliqui eingehender untersucht.

Das Ergebnis der auf diese verschiedenen Punkte gerichteten Untersuchungen soll im nachfolgenden mitgeteilt werden. Bevor dies geschieht, möge es mir aber gestattet sein, kurz einige Augaben, die sich in der Litteratur finden, vorauszuschicken.

Die Angaben des Verhaltens der Augenmuskeln und deren Insertionen sind in den älteren Lehrbüchern sehr dürftig.

So giebt $\mathrm{S}$ ö m mering ${ }^{1}$ ) an, dass sich, die vier geraden Augenmuskeln in die weisse Haut des Augapfels in gleicher Entfernung von der Homhat. verlieren. "Bei Schielenden fehlt bisweilen ciner der Geraden."

Die gleiche Angabe, dass die Insèrtion der vier geraden Augenmuskeln in gleicher Entfernung von der Cornea ist, findet sich auch bei $M$ artin $M$ ün $z^{2}$ ). Der rectus internus soll der dickste der vier recti sein.

Nach $\mathrm{Meckel}^{3}$ ) inseriert der rect. super. $3^{\prime \prime \prime}$ ïber der Cornea, rect. externus, „der dickste Augenmuskel ${ }^{*}$ inseriert einige Linien vom Hormhautrande, der obliq. super. am inneren oberen Teil der Sklera, manchmal doppelt.

Genauere Angaben finden sich bei Sömmering-Huschke. Hier heisst es, dass oberer und äusserer gerader Muskel $3^{1} / 2$ Linien, unterer und innerer etwa 3 Linien von der Hornhaut inserieren. Die Sehnenbreite des rect. sup. wird $=4$, die des infer. $=3$ und die des intern. $=4-5$ Linien angegeben, die des rect. extern. $=4$. Die Insertion des obliq. super. ist $=44^{\prime \prime \prime}$. Das vordere äussere Ende der Sehne ist gleich weit von Cornea und Optikus $=6^{\prime \prime \prime}$, hinteres inneres Ende $=8$ Linien vom. Hornhautrande. Der obliq. infer. hat eine Sehnenbreite von $4^{\prime \prime \prime}$, das vordere Ende der Insertion vom Hornhautrand 6 Linien, hinteres Ende $3^{\prime \prime \prime}$ vom Opticus, „also dem gelben Fleck sehr genähert.*

1) Sömmering, Muskellehre. 1791. S. 72.

2) Martin Münz, Handbuch der Anatomie. Muskellehre. 1815. \$. $11 \%$.

3) Meckel, menschl. Anatomie. 1820. Bd. IV. S. 105.

4) Sam. Thom. v. Söm mering, Lehrb. d. Eingeweide u. Sinnesoryane, umgearboitet $\mathrm{a}$, beendigt v. E. Huschke. 1844. Bed. III. S. 34. 
Noch genaner wird von $R$ üt $\mathrm{e}^{1}$ ) das Verhalten der Muskelinsertionen angegeben. Es inseriert der super. nach Krause 7,2, der rect. infer. 6,8, der intern. 5,2 und der rect. extern. 7,5 mm vom Hornhautrande. Das vordere Ende der Insertion des obliq. sup. ist vom oberen Hornhautrande 15,8, das hintere $20,3 \mathrm{~mm}$ entfernt, letzteres 7,9 vom hinteren Ende der Augenachse. Der Abstand des vorderen Randes der Insertion des obliq. inferior vom Hornhautrand beträgt 17, der des hinteren Randes $22 \mathrm{~mm}$. Der hintere Rand ist 2,3 vom hinteren Ende der Augenachse entfernt.

Ross ${ }^{2}$ ) sagt, „der innere gerade Augenmuskel, der stärkste, setzt sich am weitesten nach vorn an, zwei Linien entfernt vom Hornhantrande, während der obere und untere über zwei, der äussere über drei Linien vom Hornhantrand entfernt bleiben.

Hollstein ${ }^{3}$ ) erwähnt, dass die Insertion des obliq. infer. etwa drei Linien von der Eintrittsstelle des Sehnerven entfernt ist.

$\mathrm{Pilz}{ }^{4}$ ) erwähnt auch die Schrägstellung der Insertionen; er giebt an, dass „die Mittelpunkte der Insertionslinien des musc. rect. infern. und extern. im horizontalen Meridian liegen, der des super. im vertikalen, der des rect. infer. dagegen $1 / \mathrm{g}^{\prime \prime \prime}$ nach einwärts von demselben gegen die Nase zu. Der r. superior inseriert $3^{2} / 5^{\prime \prime \prime}$ vom oberen Rand der Hornhant, wobei jedoch das innere Ende seiner Aponeurose fast um $1^{\prime \prime}$ der Hornhaut näher liegt als das äussere, der rect. infer. inseriert $3^{\prime \prime \prime}$ hinter dem unteren Rand der Hornhaut mit dem äusseren Ende seiner Anheftung beinahe $1^{\prime \prime \prime}$ weiter rückwärts als mit dem inneren."

Der rect. intern. inseriert am nächsten der Hornhaut und zwar $2^{1 / 2^{\prime \prime \prime}}$ von ihrem inneren Rand entfernt, der rect. extern. $3^{1} / \mathrm{s}^{\prime \prime \prime}$ mit einer abgerundeten schmalen Sehne. Der obliq. super. hat eine bogenförmige Insertionslinie von $3^{\prime \prime \prime}$, das innere Ende ist vom optic. $3^{1 / 4}-4^{\prime \prime \prime}$ entfernt, das vordere Ende 6-7"'. Der obliq. infer. inseriert in einer mit der Konvexität nach vorn and oben gerichteten, mindestens $5^{\prime \prime}$ langen Bogenlinie, wobei das vordere Ende der Insertion 7"', das hintere 2-3"' vom Opticus entfermt ist.

Bei Henle ${ }^{1}$ ) findet sich die Angabe: „Die Insertionen der Sehnen sind nicht ganz symmetrisch, sie bilden um den Falz der Cornea einen Kreis von 12,4 mm radius, dessen Mittelpunkt sich etwas tiber $1 \mathrm{~mm}$ seitlich vom Mittelpunkt der Cornea befindet (Krause)." "Die Insertion des r. med. steht 4,5, die des lateral. beinahe $8 \mathrm{~mm}$ vom Hornhautfalze ab. Der Abstand des inferior stimmt mit dem des medialen, der des superior mit dem des lateralen. Die Insertionen der um die transversale Achse drehenden Muskeln sind um weniges aus der vertikalen Meridianebene gerückt, die des m. rect. super. etwas weniger

1) Rüte, Lehrb. d. Ophthalm. 1845. S. 9.

2) Ros s, chirurg. Anatomie. 1848.

3) Hollstein, Anatomie des Menschen. 1852. S. 286.

4) J. Pilz, Lehrb. d. Augenheilkunde. 1859. S. 54 u. ff.

5) Henle, Handh. d. Anatomie. 1866. II. Bd. 
als die des rect. infer." "Die Anheftung der Sehne des obliq. sup. an die Sehne erfolgt in einer der Achse des n. optic. ungefähr parallelen Linie von 6-7 mm Länge. Der vorderste Punkt der Anheftung liegt in der Mitte zwischen dem Hornhantfalz und der Eintrittsstelle des nerv. optic." Dor obliq. infer. inseriert zwischen der Insertion des r. lat. und der Eintrittsstelle des Sehnerven. Der hintere Endpunkt der Insertion ist nur etwas über $2 \mathrm{~mm}$ vom hinteren Endpunkt der Augenachse entfernt."

Nach Hoffmann ${ }^{1}$ ) heften sich die vier geraden Augenmuskeln etwa $1 \mathrm{~cm}$ rückwärts von dem Hornhautrande an die Sclera an. Hyrtla giebt an, dass die vier recti $2-3^{\prime \prime \prime}$ vom Hornhautrande inserieren.

Wie $\mathrm{Merkel}^{3}$ ) hervorhebt, ergiebt eine Übersicht der von einer Reihe von Autoren angegebenen Messungswerte so verschiedene Werte, dass es ihm geboten erschien, eine Reihe eigener Messungen zu machen. Die Mittelzahlen derselben treffen am nächsten mit denen von $\mathrm{K}$ ra u se zusammen, dessen Werte neben den von Merkel gefundenen in Klammer beigesetzt sind.

Der Abstand der Sehneninsertionen von dem Cornealrande beträgt nach ihm

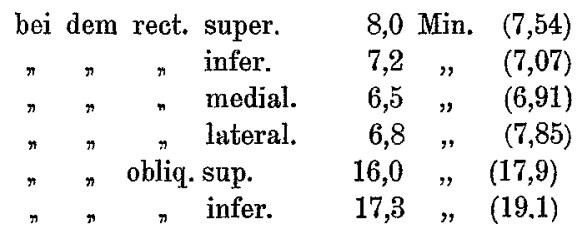

Dabei bemerkt Merkel, dass die Breite der einzelnen Sehnen nicht unbedeutenden Schwankungen unterworfen ist.

In dem Handbuch der topographischen Anatomie wird von Merkel der Abstand der Insertionslinien vom Hornhautrande sowie deren Breite nach den von E. Fuchs gefundenen Messungswerten angeführt:

Abstand der Insertion vom Hornhautrand im Mittel

$$
\begin{array}{ccll}
\text { bei } & \text { rect. sup. } & 7,7 \\
" & \Rightarrow & \text { inf. } & 6,5 \\
" & \Rightarrow & \text { medial. } & 5,5 \\
" & \Rightarrow & \text { lateral. } & 6,9
\end{array}
$$

Die Breite der Insertionslinien beträgt nach Fuchs

$$
\begin{array}{crr}
\text { bei rect. sup. } & 10,6 \\
n \quad & \text { infer. } & 9,8
\end{array}
$$$$
" \text { " medial. 10,3 }
$$$$
\text { " } " \text { lateral. } 9,2
$$

line für unseren Gegenstand wichtige Arbeit - wenigstens soweit os sich um das Auge bei Erwachsenen handelt - sind die Beiträge zur normalen

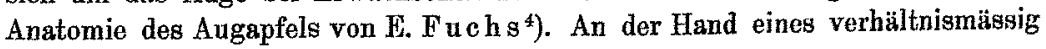

1) Hoffmann, Lehrb. d. Anatomie. 1872. II. Bd.

2) Hyrtl, Anatomie d. Menschen. 1873. S. 540 .

3) Handb. d. ges. Augenheilk. von Gräfe-Säm is ch, Makroskop. Anatomie.

4) Beiträge zur normalen Anatomie des Augapfels. Arch. f. Ophthalm. Bd. XXX, 4. Abt. \$. 1-60. 
grossen Untersuchungsmaterials wird eingehend das Verhalten der Muskelinsertionen in Bezug auf Breite, Form und Lagebeziehung erörtert, sowie auch die Lage und das nähere Verhalten der Wirbelvenen. Fuchs wurde zu diesen Untersuchungen durch die von Arlt aufgestellte Hypothese veranlasst, nach welcher die Ursache der erworbenen Myopie in einer passiven Hyperämie des Uvealtraktus anzunehmen ist. Dieselbe wird nach Arlti) „zunächst bewirkt durch Druck auf die Wirbelvenen im Bereich des musc. rect extern. $u$. obliq. infer., welche bei anhaltender Konvergenz sich geltend macht." Der leitende Gedanke bei den von Fuchs vorgenommenen Untersuchungen war der: Kann überhaupt und eventuell wo kann eine Kompression der Wirbelvenen durch die äusseren Augenmuskeln stattfinden?

Die Untersuchungen von $\mathrm{H}$. $\mathrm{Fuch}$ s haben neben dem allgemeinen anatomischen noch ein ganz speziell ophthalmologisches Interesse dadurch, dass das Ergebnis der anatomischen Untersuchung in besonderen Rubriken mitgeteilt wird für emmetropische, myopische und hypermetropische Angen. Zu bedauern ist dabei nur, dass "nur bei wenigen dieser Augen die Refraktion, welche zu Lebzeiten bestanden hatte, bekannt geworden war", „die Diagnose der Refraktion musste also hauptsächlich aus der Achsenlänge gemacht werden.* Die Berechtigung hierzu wird neuerdings von $S \operatorname{chnabel^{2}}$ ) bestritten, indem derselbe auf Grund eigener anatomischer Untersuchungen nachdrïcklich hervorhebt, dass „die Achsenlänge der meisten myopischen Augen, das ist der weit überwiegenden Mehrzahl der Augen mit niedriger und mittlerer Myopie in der Regel innerhalb derselben Grenzen schwankt, wie die Achsenlänge emmetropischer Augen." Fuchs betrachtet 31 Augen, welche eine Achsenlänge von $23-25 \mathrm{~mm}$ hatten, als emmetropisch, vier Augen mit Achsenlänge von 21-22 mm als hypermetropischen, „20 Augen waren angeblich myopisch. Bei fünf von diesen betrug die Achsenlänge zwischen 24 und $26 \mathrm{~mm}$. An diesen bulbis wurde die Myopie durch das Vorhandensein des hinteren Skleralstaphyloms und der Aderhantatrophie nächst der Papille sichergestellt. Die übrigen Augen hatten eine Achsenlänge von $26-31 \mathrm{~mm}$, sie zeigten sämtlich die Ektasie der Sklera am hinteren Pole." Diese Einteilung von Fuehs erscheint nach dem obigen nicht ganz einwandsfrei ${ }^{3}$ ).

Zum grossen Teil haben die Untersuchungen von Fuchs ein speziell ophthalmologisches Interesse. Es würde zu weit führen, an dieser Stelle hierauf einzugehen. Soweit sie ein allgemeines anatomisches Interesse haben, werden sie später bei Mitteilung des Ergebnisses meiner eigenen Untersuchungen noch Besprechung finden.

1) F. v. ArIt, Über die Ursachen und die Entstehung der Kurzsichtigkeit. 1876.

2) Über staphyloma posticum, conus u. Myopie von Schnabel und Herrnheiser, Zeitschr. f. Heilkunde. Bd. XVI. 1895.

3) 23 durch sorgfältige Untersuchung während des Lebens als emmetrop. erkannte Augen erwachsener Individuen hatten eine Achsenlänge zwischen 32 u. 25 mm. Schnabel u, Herrnheiser l, c. pag. 3 . 
Das Ergebnis meiner ejgenen, sich auf das wachsende Auge beziehenden Untersuchungen soll - wie oben bereits bemerkt in besonderen Abschnitten mitgeteilt werden. Der erste Abschnitt bezieht sich auf die Breite der Muskelinsertionen.

Was die Messung der Breite der Muskelinsertionen betrifft, so haben sowohl Merkel als auch Fuchs bereits auf die Schwierigkeit aufmerksam gemacht, die Sehnen seitlich scharf abzugrenzen. Von Merkel ${ }^{1}$ ) wird hierzu folgendes bemerkt: $1-1^{1 / 2} \mathrm{~mm}$ vor der eigentlichen Anheftung entwickeln sich reichlichere Bindegewebsmassen von ziemlich fester Beschaffenheit, welche die Sehne an den Augapfel anheften. „Dieselben erstrecken sich auch noch auf beide Kanten der platten Sehnen und so kommt es, dass eine vollständig genaue Bestimmung der Breite der letzteren eigentlich gar nicht gegeben werden kamn". ,Zu beiden Seiten der eigentlichen glänzenden Sehnenbündel zieht ein straffes Bindegewebe zum Bulbus, welches von besonderer Festigkeit ist, und das als eine Art von ,adminiculum" der Sehne aufgefasst werden muss."

Bezugnehmend auf diese Angaben Merkel's bemerkt Fuchs' ${ }^{2}$ ): "Wie Merkel beschreibt, entwickeln sich zu beiden Seiten der Sehnen reichlichere Bindegewebsmassen, welche sich fest an den Augapfel anheften und die Sehneninsertion nach beiden Seiten hin zu verlängern scheinen. "Wenn man jedoch mit der Pincette fest dieses Bindegewebe zerrt, so kann man es leicht sowohl von der Sclera als auch von der Sehne ablösen, während das Abreissen der Sehnenfasern selbst von der Sclera nur mit grosser Mühe gelingt". Nach meinen Untersuchungen kann ich das letzt Gesagte nur bestätigen.

Die beim wachsenden Auge gefundenen Messungswerte sind in beistehender Tabelle enthalten. In derselben ist in besonderer Rubrik auch noch jeweils das Wachstumsverhältnis angegehen,

1) Grâfe-8ämisch l. c. pag. 56 .

2) 1. c. pag. 10 . 
bezogen auf die Grösse der betreffenden Sehnenbreite beim Neugeborenen, wenn diese $=1$ gesetzt wird.

Beim Neugeborenen fand ich im Mittel die Sehnenbreite: beim rect. internus $=7,35(\operatorname{Max} .8,5, \quad$ Min. 6,0$)$ $" \quad, \quad$ superior $=6,95($ Max. 8,0, Min. 6,0$)$

$" \quad, \quad$ inferior $=6,25$ (Max. 7,25, Min. 5,5)

$" \quad, \quad$ externus $=5,8 \tilde{5}($ Max. 6,, 5 , Min. 5,0)

Wird die Sehnenbreite des extern. $=1$ gesetzt, so verhalten die Sehnenbreiten

$$
\begin{aligned}
& \text { des extern. : infer. : super. : internus } \\
& \text { wie } \quad-1: 1,067: 1,18: 1,25
\end{aligned}
$$

Beim erwachsenen Emmetropen betrug die Sehnenbreite im Mittel :

beim rect. intern. 10,76 (Max. 12,5, Min. 10)

$$
\begin{aligned}
& " \quad " \quad \text { super. 10,75 (Max. 11,25, Min. 10) } \\
& " \quad " \quad \text { infer. 10,35 (Max. 11,0, Min. 10) } \\
& " \quad " \quad \text { extern. 9,67 (Max. 12,0, Min. 8,3) }
\end{aligned}
$$

Hier bestand von externus : infer. : super. : internus

$$
\text { das Verhältnis wie } 1: 1,07: 1,112: 1,1125
$$

Die Reihenfolge ist geblieben, das Verhältnis der Sehnenbreiten hat sich zu Gunsten von externus und inferior geändert.

Wird die betreffende Sehnenbreite beim Neugeborenen $=1$ gesetzt, so verhält sich die Breite der Insertion beim Neugeborenen zu der bein erwachsenen Auge:

$$
\begin{gathered}
\text { bei dem internus wie } 1: 1,449 \\
" \quad " \text { superior }
\end{gathered}
$$

Die beiden bei der Geburt schmälsten Insertionen (extern u. infer.) nehmen darnach verhältnismässig mehr zu als die beiden grössten (intern. u. super.).

Wie sich das Wachstum der Sehnenbreiten in den verschiedenen Lebensabschnitten verhält, ist aus Tab. VI ersichtlich. 


\section{Tabelle VI.}

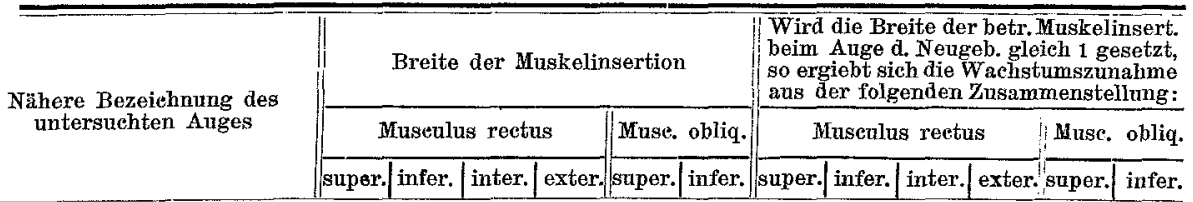

Neugebor. Kind im Mittel 20 Tage altes Kind

Knabe, 2 Monat, RA

LA

Kind, 3 Monat, RA

LA

Mädchen, $3^{1 / 2}$ Monat, RA

LA

Mädehen, $3^{1 / 2}$ Monat, LA

Kind, 11 Monat, LA

$$
\text { RA }
$$

Knabe, 1 Jahr, LA

Knabe, $1^{1 / 2}$ Jahr, RA

Knabe, $1^{3} / 4 \mathrm{Jahr}, \mathrm{LA}$

Mädchen, $2^{1 / 2}$ Jahr, LA

Knabe, $3^{1 / 2}$ Jahr, RA

Knabe, 4 Jahr, RA

Knabe, $4^{3 / 4}$ Jahr, LA

Kind, $6 \mathrm{Jahr}, \mathrm{RA}$

Mädchen, $6^{3} / 4$ Jahr, LA

Knabe, 7 Jahr, RA

Knabe, $7 \mathrm{Jahr}, \mathrm{LA}$

Knabe, 7 Jahr, RA

LA

Mädchen, $8 \mathrm{Jahr}, \mathrm{RA}$

Knabe, 81/2 Jahr, RA

Knabe, 9 Jahr, RA

Mädchen, 13 Jahr, LA

Knabe, 14 Jahr, RA

LA

Knabe, 15 Jahr, RA.

Erwachsener (Mittel)

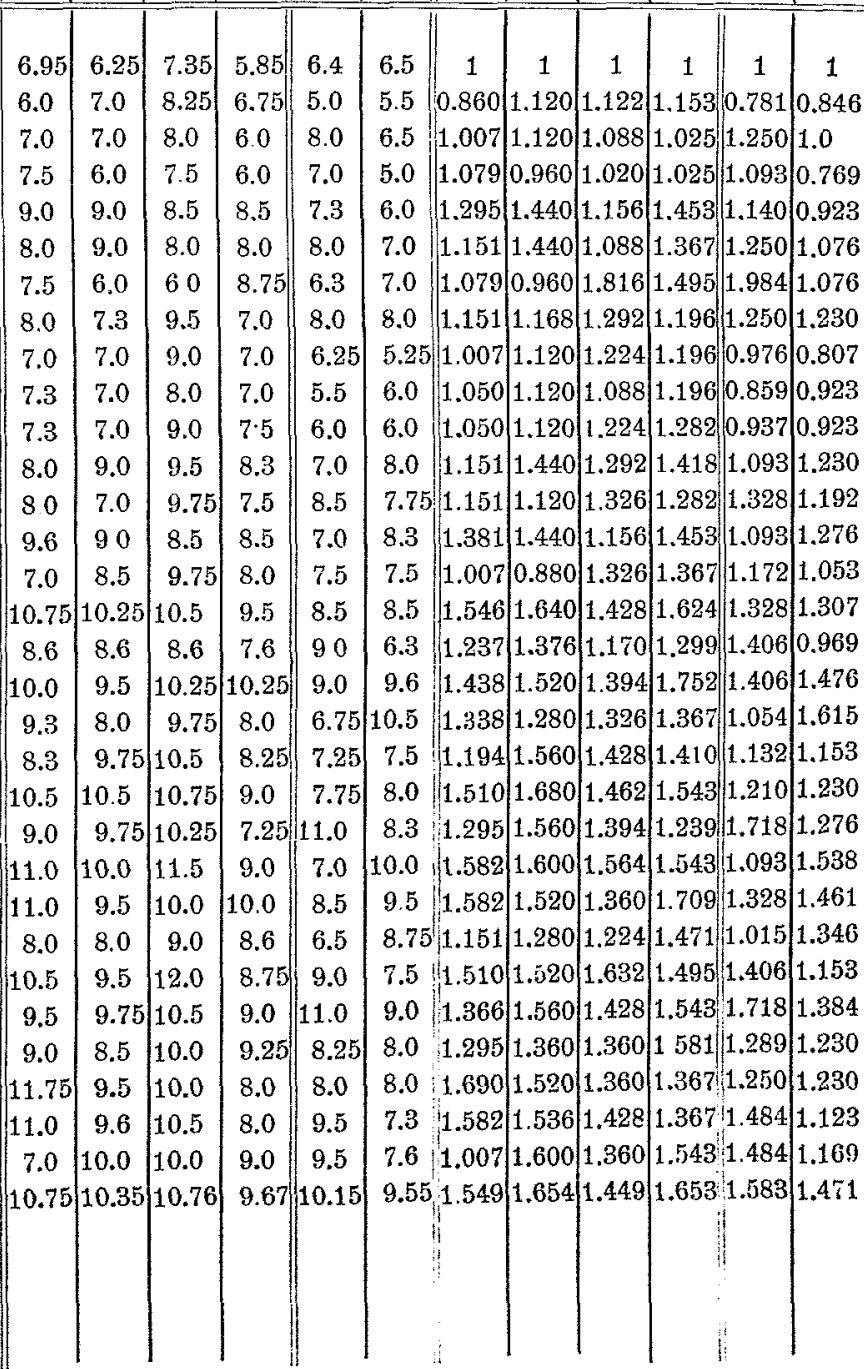


Zum Vergleich mit den gefundenen Werten seien hier noch die Zahlen angeführt, welche $\mathrm{Fu}$ chs bei 31 angeblich emmetrop. Augen fand. Nach Fuchs beträgt die Breite der Insertionsl. im Mittel: beim intern. 10,3 (Max. 12 Min. 8,8)

$\begin{array}{llll}" & & \text { super. } & 10,6(\operatorname{Max} .13,2, \operatorname{Min} .8,5) \\ , & , & \text { infer. } & 9,8(\operatorname{Max} .13,2, \operatorname{Min} .7,8) \\ " & , & \text { extern. } & 9,2(\operatorname{Max} .10,2, \operatorname{Min} .8,5)\end{array}$

Die Werte differieren nicht viel von den meinigen. Im Gegensatz zu meiner Zusammenstellung ist aber hier die Reihenfolge insofern eine etwas andere, als der super. ein wenig grösser aufgeführt ist als der intern. Dabei sei aber bemerkt, dass für 20 myop. und für 4 hyperm. Augen die Insertion des internus im Mittel grösser gefunden wurde als die des superior, nämlich $=11,4$ beim myop. und 10,2 beim hyperm. gegen 10,9 resp. 9,9 .

Werden nicht nur die 4 geraden, sondern die 6 Augenmuskeln mit einander verglichen, so war bei den 14 Neugeborenen die Ins. des intern. am breitesten 5 mal d. i. in $35,7 \%$

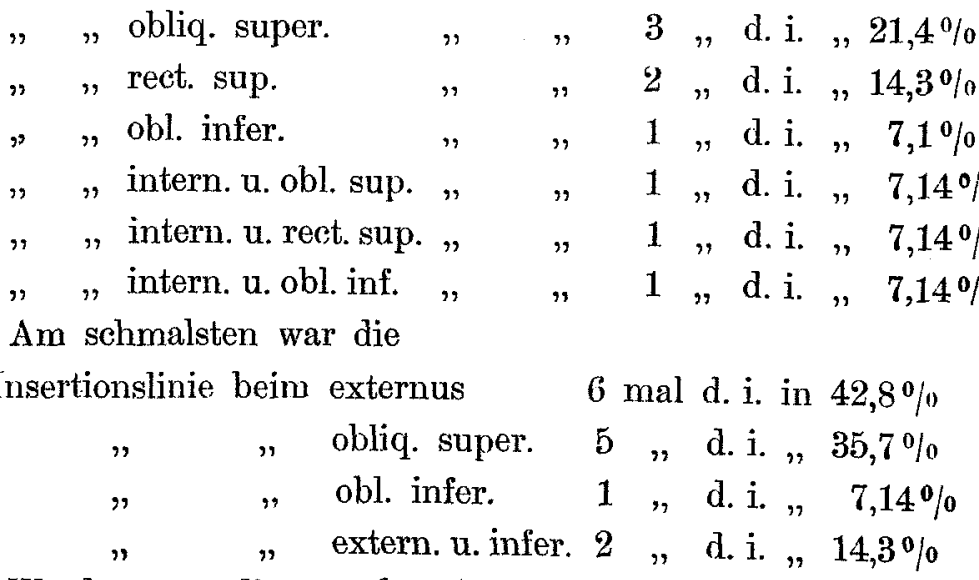

Werden nur die geraden Augenmuskel mit einander verglichen, so war am breitesten die

Insertionslinie des $\mathbf{r}$. intern.

8 mal d. i. in $57 \%$

$\begin{array}{lllll}" & \Rightarrow \text { d. r. sup. } & 3 & \text { d. i. }, & 21,5 \% \\ & \quad \text { d. r. sup. u. r. inf. } 3 & & \text { d. i. }, & 21,5 \%\end{array}$


Die Summe der Werte für die Insertionsbreite der recti ist im Mittel bei den Neugeborenen 26,39 (Max. 28,25, Min. 27,75) Erwachsenen 41,53 (Max. 46,25, Min. 39,25).

Das Verhältnis dieser Summe zu dem Äquatorialumfang beträgt bei den Neugeborenen $1: 1,95$

, erwachsenen Emmetropen $1: 1,86$.

Während bei den Neugeborenen die Insertion des rect. intern. in den meisten Fällen am grössten war, hat sich dieses Verhältnis bei den Erwachsenen etwas geändert. Hier sind super. u. intern. ziemlich gleich.

Wie von Fuchs schon hervorgehoben wird, kommen beträchtliche Variationen der Sehmenbreite vor. Aus der stärkeren oder schwächeren Entwickelung der Sehnenbreite darf man durchaus nicht auf eine stärkere bezw. sehwächere Entwickelung der Muskeln schliessen. Der Muse. rect. super. ist der schwächste entwickelte Muskel und hat mit die breiteste Insertion.

Die Insertionslinie hat eine sehr mannigfache Form, bald verläuft sie annähernd geradelinig, bald mehr oder weniger regelmässig bogenförmig, bald ist sie ganz unregelmässig etagenförmig abgesetzt, in seltenen Fällen fand ich früher schon isoliert hinter der regelrechten Insertion noch eine zweite kleine Insertion $^{1}$ ). Die Form der Insertionslimie wurde in allen Fällen mit dem Lucä'schen Apparat genau aufgezeichnet.

Was den Abstand der Insertionen von dem Hornhautrande betrifft (cf. Tabelle VII), so wurde bei der Messung derart verfahren, dass die eine Zirkelspitze an den hinteren Rand der Insertionsstelle des nach vorn umgeschlagenen Muskelstumples

1) Bei Schieloperationen ist dieser Umstand wohl zu beachten. So teilte mir vor einiger Zeit Geheimrat Maier in Karlsruhe mit, er babe bei einer Schieloperation, den Schielmuskel durchschnitten und sich nach der korrekten vollständigen Durchtrennung sehr gewundert, dass das Sehielen fast unverändert fortbestand. Der eingefuthrte Schielhacken ergab an keiner Stelle der Insertionsleiste mehr einen Widerstand; etwas hinter der Hauptinsertion war noch eine zweite ziemlich starke Insertion. 
Tabelle VII.

\begin{tabular}{|c|c|c|c|c|c|c|c|c|}
\hline \multirow{3}{*}{ Nühere Bezeiehmung des Auges } & \multicolumn{4}{|c|}{$\begin{array}{l}\text { Abstand der Mitte der In- } \\
\text { sertion der vier Reeti vom } \\
\text { Hornhautrand }\end{array}$} & \multicolumn{4}{|c|}{$\begin{array}{l}\text { Verhältniszahlen über d. Zunahme } \\
\text { des Abstandes, wenn der betr. } \\
\text { Abstand bei dem Auge des Neu- } \\
\text { geborenen gleich } 1 \text { gesetzt wird }\end{array}$} \\
\hline & \multicolumn{4}{|c|}{ Museulus rectus } & \multicolumn{4}{|c|}{ Museulus reetus } \\
\hline & super. & infer. & intern. & exter. & super. & infer. & intern. & exteru. \\
\hline Neugebor. Kind (Mittel) & 5.8 & 5.0 & 3.6 & 4.9 & 1 & 1 & 1 & 1 \\
\hline 20 Tage altes Kind & 5.75 & 5.25 & 3.75 & 5.0 & 0.991 & 1.05 & 1.041 & 1.020 \\
\hline Knabe, 2 Monat, RA & 6.5 & 5.3 & 4.0 & 5.0 & 1.120 & 1.06 & 1.111 & 1.020 \\
\hline LA & 6.3 & 5.5 & 4.0 & 5.0 & 1.086 & 1.1 & 1.111 & 1.020 \\
\hline Kind, 3 Monat, RA & 6.75 & 5.75 & 4.5 & 6.0 & 1.163 & 1.15 & 1.250 & 1.224 \\
\hline LA & 6.0 & 6.0 & 4.3 & 6.0 & 1.034 & 1.2 & 1.194 & 1.224 \\
\hline Mädchen, $3^{1 / 2}$ Monat, RA & 6.75 & 5.5 & 4.75 & 4.5 & 1.163 & 1.1 & 1.319 & 0.918 \\
\hline LA & 7.0 & 6.0 & 4.0 & 5.0 & 1.206 & 1.2 & 1.111 & 1.020 \\
\hline Mädchen, $3^{1 / 2}$ Monat, LA & 6.3 & 6.5 & 5.0 & 5.0 & 1.086 & 1.3 & 1.388 & 1.020 \\
\hline Kind, 11 Monat, LA & 6.0 & 5.0 & 3.5 & 5.5 & 1.034 & 1.0 & 0.971 & 1.122 \\
\hline RA & 6.0 & 5.0 & 3.3 & 5.5 & 1.034 & 1.0 & 0.916 & 1.122 \\
\hline Knabe, I Jahr, LA & 7.0 & 5.0 & 5.0 & 6.0 & 1.206 & 1.0 & 1.388 & 1.244 \\
\hline Knabe, $11 / 2$ Jahr, RA & 8.0 & 6.75 & 4.5 & 6.0 & 1.379 & 1.35 & 1.194 & 1.244 \\
\hline Knabe, $1^{3 / 4}$ Jahr, LA & 7.5 & 6.5 & 5.75 & 6.0 & 1.293 & 1.3 & 1.597 & 1.244 \\
\hline Mädchen, $21 / 2$ Jahr, LA & 7.0 & 6.25 & 5.0 & 6.0 & 1.206 & 1.25 & 1.388 & 1.244 \\
\hline Knabe, 31/2 Jahr, RA & 8.0 & 6.75 & 5.0 & 7.0 & 1379 & 1.35 & 1.388 & 1.428 \\
\hline Knabe, 4 Jahr, RA & 7.5 & 5.0 & 5.25 & 6.6 & 1.293 & 1.0 & 1.458 & 1.347 \\
\hline Knabe, $4^{3} / 4$ Jahr, LA & 7.3 & 7.25 & 4.75 & 7.0 & 1.258 & 1.45 & 1.319 & 1.428 \\
\hline Kind, 6 Jahr, RA & 7.5 & 7.0 & 5.5 & 6.5 & 1.293 & 1.4 & 1.528 & 1.326 \\
\hline Mädchen, $6^{3} / 4$ Jahr, LAA & 6.25 & 6.0 & 4.0 & 625 & 1.077 & 1.2 & 1.111 & 1.275 \\
\hline Knabe, 7 Jahr, RA & 6.75 & 6.5 & 5.0 & 6.5 & 1.163 & 1.3 & 1.388 & 1.326 \\
\hline Knabe, 7 Jahr, LA & 7.0 & 6.5 & 5.0 & 6.75 & 1.206 & 1.3 & 1.388 & 1.377 \\
\hline Knabe, 7 Jahr, RA & 10.0 & 7.3 & 6.0 & 7.0 & 1.724 & 1.46 & 1.666 & 1.428 \\
\hline LA & 9.0 & 7.5 & 6.3 & 7.0 & 1.551 & 1.5 & 1.750 & 1.428 \\
\hline Mädchen, 8 Jahr, RA & 7.3 & 6.6 & 5.25 & 6.25 & 1.258 & 1.32 & 1.458 & 1.275 \\
\hline Knabe, $8^{1 / 2}$ Jahr, RA & 9.5 & 8.0 & 7.0 & 8.5 & 1.638 & 1.6 & 1.944 & 1.734 \\
\hline Knabe, 9 Jahr, RA & 8.0 & 7.5 & 5.0 & 7.0 & 1.379 & 1.5 & 1.388 & 1.428 \\
\hline Mädchen, 13 Jahr, LA & 7.0 & 7.0 & 5.3 & 6.25 & 1.206 & 1.4 & 1.472 & 1.275 \\
\hline Knabe, 14 Jahr, RA & 8.5 & 7.0 & 4.75 & 6.5 & 1.465 & 1.4 & 1.319 & 1.326 \\
\hline LA & 8.0 & 6.6 & 4.5 & 7.0 & 1.379 & 1.32 & 1.250 & 1.428 \\
\hline Knabe, $15 \mathrm{Jahr}$, RA & 8.25 & 8.0 & 5.5 & 7.25 & 1.422 & 1.6 & 1.528 & 1.459 \\
\hline Erwachsener (Mittel) & 8.01 & 6.85 & 5.85 & 6.75 & 1.358 & 1.378 & 1.629 & 1.374 \\
\hline
\end{tabular}


gesetyt wurde, die andere an den Limbus; gemessen wurde stets sowohl won der Mitte der Insertion als auch von den beiden Endpunkten; auf diese Weise wurde vielfach der bogenförmige Verlauf der Insertion und auch die Schrägstellung derselben festgestellt. Indem man vón dem Hornhautrand als Ausgangspunkt der Messung den Abstand der Insertion misst, muss man - wie Fuchs bemerkt - beachten, dass die Hornhaut kein Kugelsegment bildet und an verschiedenen Stellen ungleich weit von dem Äquator entfernt ist, in dem Horizontaldurchmesser näher, oben und unten weiter weg.

Der Abstand der Insertion der geraden Augenmuskeln vom Hornhautrand wurde individuell sehr verschieden gefunden, dabei ergab aber die Messung, dass der Abstand für den rect. super ausnahmslos am grössten und der Abstand für den rect. intern. ausnahmslos der kleinste war, die Insertionen von extern. und von infer. waren bald gleich weit vom Hornhautrande entfernt, bald war die eine, bald die andere diesem etwas näher. Im allgemeinen ist es richtig, was Fuchs angiebt, dass, wemn für eine Sehne die Distanz von der Hornhaut klein ist, dies auch für die übrigen Sehnen gilt.

Den Abstand der Insertion vom Hornhautrand fand ich beim Neugeborenen

im Mittel bei dem rect. intern. 3,6 (Max. 4,3, Min. 3,0), rect. extern. $4,9(\operatorname{Max} .5,75$, Min. 4,0), rect. infer. 5,0 (Max. 5,5, Min. 4,0), rect. sup. $5,8(\operatorname{Max} .7,0, \quad$ Min. 5,0),

beim Erwachsenen im Mittel

b. d. rect. intern. 5,85 (Max. 6,75, Min. 5,0),

$$
\begin{aligned}
& " \quad " \quad \text { extern. 6,75 (Max. 7,75, Min. 6,25), } \\
& " \quad " \quad \text { intern. 6,85 (Max. 7,5, Min. 6,0), } \\
& " \quad " \quad \text { super. 8,01 (Max. 9,0, Min. 6,75). }
\end{aligned}
$$

Es verhielten sich die Abständo der vier recti in angegrebener 
Reihenfolge bei dem Neugeborenen wie $1: 1,36: 1,4: 1,6$ Erwachsenen $\quad, 1: 1,15: 1,17: 1,36$

Wird der Abstand der einzelnen Insertionen beim Neugeborenen und beim Erwachsenen mit einander verglichen, so ergiebt sich, dass beim internus der Abstand um das 1,63 fache, bei dem superior um das 1,36 fache, bei extern. $n$. infer. um das 1,37 fache wächst. Wemn umfangreichere Untersuchungen dieses Verhalten bestätigen, so würde das heissen, dass der Abstand der Insertion des intern. vom Hornhautrande erheblicher zunimmt als bei den drei anderen geraden, wobei ich dahingestellt lasse, ob dies mit den Konvergenzbewegungen des Auges in Zusammenhang zu bringen ist.

Bei dieser Gelegenheit möchte ich nur erwähnen, dass Sch ön ${ }^{1}$ ) bei dem myopischen Auge eine Lageverschiebung des Schlem mschen Kanals auf der temporalen und auf der nasalen Seite gefunden hat derart, dass derselbe auf der nasalen merklich nach rückwärts gerückt war und auf der temporalen ein wenig nach vorn. Schön deutet dieses Verhalten so, dass er annimmt, der „Zug des Rectus jnternus wirke zunächst auf die Sklera und zwar auf einen der Breite des Muskelansatzes entsprechenden bandartigen Streifen im horizontalen Meridian, dann pflanze sich der Zug auf die Hornhaut und die gegenüberliegende Sklera fort und werde sich auch hier überall im horizontalen Meridian am fülllbarsten machen. Die von dem Zug betroffenen Teile werden die Neigung erhalten, sich im Sinne der Zugrichtung gegen die benachbarten, daneben oder darunter liegenden Gebilde zu verschieben."

Auf die gleiche Ursache wird von Schön und von Förster der scheinbare Strabismus convergens bezogen, der infolge des Negativwerdens des Winkels $\alpha^{2}$ ) bei manchen Myopen zur Be-

1) Schön, Eine neue Verzerrungserscheinung am kurzsichtigen Auge. Ophthalm. Kongress, 1889. S. 85 u. ff.

2) Winkel zwischen Gesichtslinie und Hornhantachse. Förster ist zu einer ähnlichen Erklärung in Bezug auf die Veränderung des Winkels $\alpha$ gekommen. 1. c. pag. 89 . 
obachtung kommt, durch den Zug soll die Hornhautachse nach innen von der Gesichtslinie verschoben werden.

Eine stärkere Zunahme des Abstandes der Insertion des internus von dem Hornhautrande würde mit dem Vorstehenden in Einklang stehen.

Was die Entfernung der Recti-Insertionen von dem Sehnerven betrifft, so giebt Tabelle VIII darüber Aufschluss. Es ist aus derselben auch das Wachstum der betr. Abstände in den verschiedenen Lebensabschnitten ersichtlich.

Bei dem Neugeborenen wurde der mit dem Zirkel von der hinteren Insertionslinie bis zum Sehnervenumfang gemessene Abstand im Mittel

$$
\begin{aligned}
& \text { bei dem rectus intern. }=10,5 \\
&, \quad, \quad \text { rectus infer. }=11,10 \\
& " \quad, \quad \text { rectus super. }=11,45 \\
&, \quad, \quad \text { rectus extern. }=13,10 \text { gefunden. }
\end{aligned}
$$

In allen 14 Fällen war der Abstand bei dem intern. am kleinsten, bei dem extern. am grössten, in vier Fällen beim sup. ebenso klein wie bei dem intern. Die Abstände verhalten sich der des intern. = 1 gesetzt, wie $1: 1,06: 1,09: 1,25$.

Bei dem Erwachsenen war der Abstand im Mittel

$$
\begin{aligned}
\text { bei } \text { dem rectus intern. } & =16,95 \\
" \quad & \text { rectus super. }=18,51 \\
" \quad & \text { rectus infer. }=18,80 \\
, \quad & \text { rectus extern. }=20,6
\end{aligned}
$$

Sie verhalten sich demnach wie $1: 1,09: 1,11: 1,21$.

Wie man daraus ersieht, hat sich das Verhältnis von intern. : super. u. : extern. nicht wesentlich geändert.

Vergleicht man die betreffenden Abstände beim Neugeborenen und beim Erwachsenen miteinander, so findet man für alle vier annähernd das gleiche Wachstumsverhältnis, nämlich 
Tabelle VIII.

\section{Abstand der Mitte der Insertionen vom Opticus-Umfang.}

\begin{tabular}{|c|c|c|c|c|c|c|c|c|}
\hline & \multirow{2}{*}{$\begin{array}{l}\text { Reet. } \\
\text { sup. }\end{array}$} & \multirow{2}{*}{$\begin{array}{l}\text { Reet. } \\
\text { inf. }\end{array}$} & \multirow{2}{*}{$\begin{array}{c}\text { Rect. } \\
\text { int. }\end{array}$} & \multirow[t]{2}{*}{$\begin{array}{c}\text { Rect. } \\
\text { ext. }\end{array}$} & \multicolumn{4}{|c|}{$\begin{array}{l}\text { Verhältniszahlen, wem der be- } \\
\text { treff. Wert bei dem Ange des } \\
\text { Neugeb. }=1.0 \text { gesetzt wird }\end{array}$} \\
\hline & & & & & $\begin{array}{l}\text { Reet. } \\
\text { sup. }\end{array}$ & $\begin{array}{c}\text { Rect, } \\
\text { inf. }\end{array}$ & $\begin{array}{c}\text { Reet. } \\
\text { int. }\end{array}$ & $\begin{array}{c}\text { Rect. } \\
\text { ext. }\end{array}$ \\
\hline Neugeborener (Mittel) & 11.45 & 11.1 & 10.5 & 13.1 & 1.0 & 1.0 & 1.0 & 1.0 \\
\hline 20 Tage altes Kind & 13.0 & 11.3 & 10.5 & 14.25 & 1.135 & 1.018 & 1.0 & 1.087 \\
\hline Knabe, 2 Monat, RA & 13.0 & 11.0 & 10.5 & 13.3 & 1.135 & 1.0 & 1.0 & 1.015 \\
\hline LA & 12.75 & 11.0 & 10.3 & 13.0 & 1.113 & 1.0 & 0.980 & 0.992 \\
\hline Kind, 3 Monat, RA & 130 & 12.5 & 11.5 & 14.0 & 1.135 & 1.126 & 1.095 & 1.068 \\
\hline LA & 13.0 & 12.75 & 12.0 & 15.5 & 1.135 & 1.149 & 1.142 & 1.183 \\
\hline Mädchen, 31/2 Monat, RA & 12.5 & 13.0 & 11.75 & 15.5 & 1.091 & 1.171 & 1. & 1.183 \\
\hline LA & 12.5 & 13.5 & 12.0 & 14.0 & 1.091 & 1.216 & 1.142 & 1.068 \\
\hline Mädehen, $3^{1 / 2}$ Monat, LA & 12.5 & 12.0 & 11.5 & 13.25 & 1.091 & 1081 & 1.095 & 1.011 \\
\hline Kind, 11 Monat, LA & 13.0 & 12.0 & 11.0 & 14.0 & 1.135 & 1.081 & 1.047 & 1.068 \\
\hline RA & 13.0 & 12.0 & 10.75 & 14.0 & 1.135 & 1.081 & 1.023 & 1.068 \\
\hline Knabe, 1 Jahr, LA & 13.6 & 13.3 & 11.5 & 16.0 & 1.187 & 1.195 & 1.095 & 1.216 \\
\hline Knabe, $1^{1 / 2} \mathrm{Jahr}, \mathrm{RA}$ & 16.0 & $1 \check{5} .0$ & 14.0 & 17.0 & 1.397 & 1.351 & 1.333 & 1.297 \\
\hline Knabe, $1^{3 / 4}$ Jahr, LA & 15.0 & 13.0 & 12.0 & 15.5 & 1.310 & 1.171 & 1.142 & 1.183 \\
\hline Mädchen, $2^{1} / 2$ Jahr, LA & 14.0 & 13.0 & 13.0 & 15.25 & 1.222 & 1.171 & 1.238 & 1.164 \\
\hline Knabe, $3^{1 / 2}$ Jahr, RA & 17.0 & 16.5 & 13.5 & 17.0 & 1.484 & 1.483 & 1.285 & 1.297 \\
\hline Knabe, 4 Jahr, RA & 17.0 & 16.5 & 14.5 & 18.25 & 1.484 & 1.483 & 1.380 & 1.393 \\
\hline Knabe, $4^{3} ; *$ Jahr, LA & 16.3 & 15.5 & 15.0 & 18.0 & 1.423 & 1.393 & 1.428 & 1.374 \\
\hline Kind, 6 Jahr, RA & 17.5 & 16.3 & 15.5 & 18.6 & 1.528 & 1.468 & 1.476 & 1.419 \\
\hline Mädchen, $6^{3} / \pm$ Jahr, LA & 16.0 & 15.0 & 14.0 & 18.0 & 1.397 & 1.351 & 1.333 & 1.374 \\
\hline Knabe, 7 Jahr, RA & 16.75 & 16.5 & 15.0 & 17.0 & 1.463 & 1.483 & 1.428 & 1.297 \\
\hline Knabe, 7 Jahr, LA & 15.5 & 15.25 & 13.5 & 17.5 & 1.353 & 1.373 & 1.285 & 1.335 \\
\hline Knabe, 7 Jahr, RA & 19.0 & 16.3 & 13.0 & 20.0 & 1.659 & 1.468 & 1.235 & 1.526 \\
\hline LA & 18.5 & 17.0 & 15.0 & 20.0 & 1.615 & 1.531 & 1.428 & 1.526 \\
\hline hen, 8 Jahr, RA & 16.5 & 14.75 & 13.75 & 17.75 & 1.441 & 1.328 & 1.309 & 1.354 \\
\hline Knabe, 8/2 Jahr, RA & 17.5 & 17.0 & 16.0 & 18.25 & 1.528 & 1.531 & 1.523 & 1.393 \\
\hline Knabe, 9 Jahr, RA & 15.75 & 16.0 & 15.0 & 18.0 & 1.357 & 1.441 & 1.428 & 1.374 \\
\hline Mädchen, 13 Jahr, LA & 16.0 & 15.75 & 14.3 & 18.0 & 1.397 & 1.418 & 1.361 & 1.374 \\
\hline Knabe, 14 Jahr, RA & 15.5 & 13.0 & 14.0 & 16,0 & 1.353 & 1.171 & 1.333 & 1.216 \\
\hline LA & 15.3 & 15.0 & 14.0 & 17.0 & 1.336 & 1.351 & 1.333 & 1.297 \\
\hline RA & 16.75 & 16.25 & 15.5 & 18.0 & 1.463 & 1.463 & 1.476 & 1.374 \\
\hline lirwachsener (Mittel) & 18.51 & 18.80 & 16.95 & 20.6 & 1.616 & 1.605 & 1.612 & 1.573 \\
\hline
\end{tabular}




$$
\begin{aligned}
& \text { bei dem rect. intern. }=1,612 \\
& " \quad, \quad \text { rect. super. }=1,616 \\
& , \quad, \quad \text { rect. infer. }=1,605 \\
& , \quad, \quad \text { rect. extern. }=1,573
\end{aligned}
$$

Wenn weitere Untersuchungen dieses Verhalten bestätigen, so würde das heissen, der hintere Abschnitt des Auges, von den Insertionen der recti an, wächst - wenn es sich um emmetropische Augen handelt - ziemlich proportional.

Eine besondere Besprechung bedarf die Schrägstellung der Insertionen der recti. Wie oben schon angegeben, wurde stets derart gemessen, dass jeweils der Abstand von der Mitte der Insertion und von deren Endpunkten zur Hormhaut bestimmt wurde. Während die Zahlen in Tabelle VII sich auf die Mitte der Insertion bezogen, ist in Tabelle IX a bei rectus super. und infer. der Abstand vom temporalen bezw. nasalen Rande der Insertion angegeben, sowie bei rectus internus und externus vom oberen und unteren Ende derselben. Der mehr oder weniger stark bogenförmige Verlauf der Insertionen wurde, wie oben schon angegeben, in allen Fällen von allen Muskeln mit dem Lucä'schen Apparat aufgezeichnet.

Aus den gewonnenen Messungswerten wurde damn der Winkel berechnet, welchen eine dureh die beiden Endpunkte der Insertion gelegte gerade Linie auf die Ebene bezogen mit dem Hornhautrande bezw. mit dem Äquator bildet (cf. Tabelle IX b).

Bei rectus super. und infer. ist die Schrägstellung stets gleichsinnig, nur von wechselndem Grade der Art, dass beim super. die Schrägstellung stark sein kann, bei dem infer. gering und umgekehrt. Stets ist das mediale Ende der Insertion dem Hornhautrande näher als das temporale.

Die Schrägstellung bei internus und externus ist im allgemeinen nur gering, dabei ist die Schrägstellung eine entyregengesetzte; bei dem rect. internus war das obere Ende der Insertion 
Tabelle IXa.

\begin{tabular}{|c|c|c|c|c|c|c|c|c|}
\hline \multirow{3}{*}{ Name und Alter des Kindes } & \multicolumn{2}{|c|}{$\begin{array}{l}\text { Reetus } \\
\text { superior }\end{array}$} & \multicolumn{2}{|c|}{$\begin{array}{l}\text { Rectus } \\
\text { inferior }\end{array}$} & \multicolumn{2}{|c|}{$\begin{array}{c}\text { Rectus } \\
\text { internus }\end{array}$} & \multicolumn{2}{|c|}{$\begin{array}{c}\text { Rectuss } \\
\text { externus }\end{array}$} \\
\hline & \multicolumn{8}{|c|}{ Abstand der Sehnenenden vom Hornhautrand } \\
\hline & 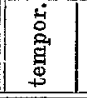 & 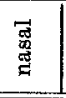 & 总 & $\begin{array}{l}\text { 急 } \\
\text { 光 }\end{array}$ & $\begin{array}{l}8 \\
\frac{1}{0} \\
\text { : }\end{array}$ & 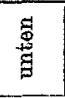 & \%ั & $\begin{array}{l}\text { 苞 } \\
\text { 害 }\end{array}$ \\
\hline Neugeborener (Mittel) & 7.07 & 5.6 & 6.63 & 4.85 & 4,45 & 4.77 & 5.5 & 5.4 \\
\hline x. 103, 20 Tage altes Kind & & & & & & & & \\
\hline LA & 7.0 & 5.3 & 6.25 & 5.0 & 4.0 & 4.75 & 6.0 & 5.25 \\
\hline Knabe L., 8 Wooh. alt, RA & 8.0 & 6.3 & 7.0 & 5.0 & 5.0 & 4.75 & 6.0 & 6.5 \\
\hline$I_{1} A$ & 7.0 & 6.0 & 7.0 & 5.0 & 4.5 & 4.5 & 6.0 & 5.5 \\
\hline 3 monatl. Kind RA & 8.5 & 7.0 & 8.5 & 6.75 & 5.0 & 6.3 & 6.75 & 6.75 \\
\hline IsA & 8.0 & 7.0 & 8.0 & 7.0 & 5.0 & 6.0 & 7.0 & 6.5 \\
\hline Louise R., $3^{1 / 2}$ Monat, RA & 8.0 & 6.5 & 6.0 & 5.5 & 4.5 & 5.0 & 6.5 & 6.25 \\
\hline LA & 8.25 & 7.5 & 7.75 & 5.25 & 5.0 & 5.5 & 5.5 & 6.0 \\
\hline Lina J., $3^{1} / 2$ Monat, LA & 7.25 & 6.75 & 7.5 . & 5.5 & 5.0 & 7.0 & 6,5 & 6.25 \\
\hline 11 monatliches Kind, RA & 7.0 & 6.3 & 7.0 & 5.3 & 5.0 & 5.0 & 6.0 & 6.0 \\
\hline LA & 7.0 & 6.5 & 7.0 & 4.5 & 5.0 & 5.0 & 6.0 & 5.75 \\
\hline August W, 1 Jahr alt, LA & 9.0 & 7.0 & 8.0 & 6.0 & 6.0 & 6.75 & 7.5 & 7.0 \\
\hline Camillus $\mathrm{H} ., 1^{1} / \mathrm{s}$ Jahr, RA & 10.5 & 8.3 & 9.0 & 7.5 & 6.75 & 6.25 & 6.5 & 7.0 \\
\hline Erwin A., $1^{3} / 4$ Jahr, LA & 9.0 & 7.3 & 9.0 & 6.3 & 6.0 & 6.5 & 7.5 & 7.0 \\
\hline Eugenie R., $2^{1} / 2$ Jahr, LA & 8.0 & 6.5 & 7.5 & 6.5 & 6.0 & 6.3 & 6.75 & 6.0 \\
\hline Ludwig B., $3^{1 / 2}$ Jahr, RA & 10.0 & 8.0 & 10.75 & 6.0 & 7.0 & 6.0 & 8.0 & 8.0 \\
\hline Max T., 4 Jahr, RA & 9.0 & 6.5 & 7.6 & 5.25 & 5.6 & 6.3 & 7.6 & 7.3 \\
\hline Fugen M., $4^{3} / 4$ Jahr, LA & 9.6 & 7.25 & 10.3 & 7.3 & 5.75 & 6.5 & 7.6 & 7.6 \\
\hline E., $6 \mathrm{Jahr}, \mathrm{RA}$ & 8.75 & 7.0 & 9.9 & 6.5 & 5.6 & 6.6 & 7.25 & 7.12 \\
\hline Louise R., $6^{3} / 4 \mathrm{Jahr}$, LA & 8.0 & 5.5 & 8.75 & 5.6 & 5.0 & 5.75 & 6.75 & 7.25 \\
\hline Joseph R, 7 Jahr, RA & 9.5 & 6.75 & 105 & 6.5 & 6.25 & 7.0 & 7.5 & 8.0 \\
\hline Leo Z., 7 Jahr, LA & 8.9 & 7.25 & 8.3 & 6.9 & 5.6 & 6.25 & 7.5 & 7.25 \\
\hline Knabe, 7 Jahr RA & 11.0 & 9.0 & 10.3 & $8 \cdot 0$ & 9.0 & 8.5 & 8.0 & 8.0 \\
\hline LA & 10.5 & 9.0 & 10.12 & 8.0 & 7.5 & 8.0 & 8.0 & 8.5 \\
\hline Henr. E., 8 Jahr, RA & 8.75 & 7.0 & 8.6 & 7.25 & 5.75 & 6.0 & 7 & 7 \\
\hline Theodor B., 81/2 Jahr, RA & 12.0 & 9.0 & 10.5 & 8.0 & 9.0 & 9.5 & 10.5 & 9.25 \\
\hline Karl C, 9 Jahr, RA & 9.75 & 9.0 & 10.0 & 8.0 & 7.0 & 7.0 & 8.5 & 8.5 \\
\hline Marie P., 13 Jahr, LA & 9.0 & 6.75 & 8.75 & 6.75 & 6.6 & 7.6 & 7.6 & 7.5 \\
\hline Eugen B , 14 Jahr, RA & 11.0 & 8.0 & 7.5 & 7.3 & 5.5 & 6.75 & 7.0 & 7.0 \\
\hline LA & 10.5 & 8.3 & 9.0 & 8.0 & 6.0 & 8.0 & 8.0 & 8.0 \\
\hline $\begin{array}{l}\text { Paul K., } 15 \text { Jahr, RA } \\
\text { Erwachsener Himmetrop }\end{array}$ & 9.25 & 7.25 & 10.25 & 6 & 7.75 & 7.25 & 7.75 & 7.75 \\
\hline
\end{tabular}


Tabelle IX b.

\section{Schrägstellung der Insertion der 4 Recti in Bezug auf den Hornhautrand.}

(Ausgedrückt durch den Winkel, den die Insertion mit der Äquatorialebene bildet.)

\begin{tabular}{|c|c|c|c|c|}
\hline Bezeichnung der Augen & Recti sup. & Recti inf. & Recti int. & Recti ext. \\
\hline $\begin{array}{l}\text { Auge des Neugeborenen } \\
\text { (Mittel) }\end{array}$ & $12^{0} 11^{\prime}$ & $16^{\circ} 30^{\prime}$ & $\begin{array}{l}\text { oberer Rand der } \\
\text { Insert. liegtgew. } \\
\text { näher d. Hornh.' } \\
\quad+2^{0} 28^{\prime}\end{array}$ & $\begin{array}{l}\text { inner. Rand liegt } \\
\text { d. Hornhautrand } \\
\text { gewöhnl. näher } \\
-0^{0} 58^{\prime}\end{array}$ \\
\hline 20 Tage altes Kind & $16^{\circ} 23^{\prime}$ & $10^{\circ} 16^{\prime}$ & $+5^{0} 13^{\prime}$ & $-6^{0} 23^{4}$ \\
\hline Knabe, 2 Monate, RA & $14^{0} 4^{\prime}$ & $16^{\prime \prime} 33^{\prime}$ & $-1^{0} 46^{\prime}$ & $+4^{0} 45$ \\
\hline LA & $7^{0} 38^{\prime}$ & $19^{\circ} 27^{\circ}$ & 0 & $-4^{0} 45^{\prime}$ \\
\hline Kind, 3 Monate, RA & $9^{0} 34^{\prime}$ & $11^{0} 10^{\prime}$ & $+8^{0} 48^{\prime}$ & 0 \\
\hline LA & $7^{0} 38^{\prime}$ & $6^{0} 22^{\prime}$ & $+7^{0} 38^{\prime}$ & $-3^{0} 36^{\prime}$ \\
\hline Mädchen, $3^{1} / 2$ Monat, RA & $11^{0} 33^{\prime}$ & $4^{0} 45^{\prime}$ & $+4^{0} 46^{\prime}$ & $-1^{0} 36^{\prime}$ \\
\hline IAA & $5^{0} 20^{\prime}$ & $20^{\circ}$ & $+2^{0} 59^{\prime}$ & $+4^{0} 4^{\prime}$ \\
\hline Mädchen, $3^{1} / 2$ Monat, LA & $4^{0} 4^{\prime}$ & $16^{0} 32^{\prime}$ & $+12^{0} 50^{\prime}$ & $-2^{0}$ \\
\hline Kind, 11 Monat, LA & $3^{0} 54^{\prime}$ & $20^{\circ} 54^{\prime}$ & 0 & $\div 2^{0}$ \\
\hline $\mathrm{RA}$ & $5^{0} 30^{\prime}$ & $12^{0} 57^{\prime}$ & 0 & 0 \\
\hline Knabe, 1 Jahr, LA & $14^{0} 28^{\prime}$ & $12^{0} 50^{\circ}$ & $+4^{0} 31^{\prime}$ & $-3^{0} 26^{\prime}$ \\
\hline Knabe, $1^{1 / 2} \mathrm{Jahr}, \mathrm{RA}$ & $15^{0} 58^{\prime}$ & $12^{0} 21^{\prime}$ & $-2^{0} 55^{\prime}$ & $+3^{0} 47^{\prime}$ \\
\hline Knabe, $1^{3} / 4$ Jahr, LA & $10^{0} 11^{\prime}$ & $17^{0} 28^{\prime}$ & $+3^{0} 19^{\prime}$ & $-3^{0} 19^{\prime}$ \\
\hline Mädchen, $2^{1} / 2$ Jahr, LA & $12^{0} 21^{\prime}$ & $10^{0} 25^{\prime}$ & $+1^{0} 43^{\prime}$ & $-5^{0} 20^{\prime}$ \\
\hline Knabe, $3^{1 / 2}$ Jahr, RA & $10^{0} 43^{\prime}$ & $27^{0} 35^{\prime}$ & $-5^{0} 26^{\prime}$ & 0 \\
\hline Knabe, 4 Jahre, RA & $16^{0} 51^{\prime}$ & $15^{0} 51^{\prime}$ & $+4^{0} 38^{\prime}$ & $-2^{0} 14^{\prime}$ \\
\hline Knabe, $4^{3 / 4}$ Jahr, LA & $13^{0} 36^{\prime}$ & $18^{\circ} 22^{\prime}$ & $+4^{0} 11^{\prime}$ & 0 \\
\hline Kind, 6 Jahr, RA & $10^{0} 50^{\prime}$ & $18^{0} 11^{\prime}$ & $+5^{0} 51^{\prime}$ & $-1^{0} 46^{\prime}$ \\
\hline Mädchen, $6^{3} / 4 \mathrm{Jahr}, \mathrm{LA}$ & $17^{0} 31^{\prime}$ & $18^{0} 30^{\prime}$ & $+4^{0} 4^{\prime}$ & $+3^{0} 26^{\prime}$ \\
\hline Knabe, $7 \mathrm{Jahr}, \mathrm{RA}$ & $15^{0} 8^{\prime}$ & $22^{\circ} 26^{\prime}$ & $-3^{0} 57^{\prime}$ & $+3^{0} 9^{\prime}$ \\
\hline Knabe, 7 Jahr, LA & $4^{0} 45^{\prime}$ & $13^{0} 36^{\prime}$ & $+3^{0} 36^{\prime}$ & $-1^{0} 57^{\prime}$ \\
\hline Knabe, 7 Jahr, RA & $10^{\circ} 25^{\prime}$ & $13^{\circ} 18^{\prime}$ & $+2^{0} 28^{\prime}$ & 0 \\
\hline LA & $7^{0} 49^{\prime}$ & $12^{0} 8^{\prime}$ & $+2^{\circ} 51^{\prime}$ & $+2^{0} 51^{\prime}$ \\
\hline Mädchen, $8 \mathrm{Jahr}, \mathrm{RA}$ & $12^{0} 11^{\prime}$ & $9^{0} 40^{\prime}$ & $+1^{0} 32^{\circ}$ & 0 \\
\hline Knabe, $8^{1 / 2} \mathrm{Jahr}$, RA & $16^{0} 33^{4}$ & $15^{0} 13^{\prime}$ & $+2^{0} 21^{\prime}$ & $-8^{\circ} 10^{\prime}$ \\
\hline Knabe, 9 Jahr, RA & $4^{0} 32^{\prime}$ & $11^{0} 50^{\prime}$ & 0 & 0 \\
\hline Mädchen, 13 Jahr, LA & $14^{0} 27^{\prime}$ & $13^{0} 36^{\prime}$ & $+5^{0} 44^{\prime}$ & $-0^{0} 34^{\prime}$ \\
\hline Knabe, $14 \mathrm{Jahr}, \mathrm{RA}$ & $14^{\circ} 47^{\prime}$ & $1^{0} 12^{\prime}$ & $+7^{0} 10^{\prime}$ & 0 \\
\hline LA & $11^{\circ} 33^{\prime}$ & $5^{0} 88^{\prime}$ & $+10^{\circ} 57^{\prime}$ & 0 \\
\hline Knabe, $15 \mathrm{Jahr}, \mathrm{RA}$ & $16^{0} 32^{\prime}$ & $25^{0} 9^{\prime}$ & $-2^{*} 51^{\prime}$ & 0 \\
\hline Birwachsener (Mittel) & $11^{\circ} 42^{\prime}$ & $14^{0} 4^{\prime}$ & $+3^{0} 43^{\prime}$ & 0 \\
\hline
\end{tabular}

1) Bei internus und externus bedeutet das positive Vorzeichen. dass das obere Hnde der Insertion dem Hornhautrande näher steht; bei dem internus ist das obere Ende der Insertion 23 mal näher, 5 mal entfernter als der untere; $4 \mathrm{mal}$ sind beide gleich weit entfernt. Bei dem externus ist las obere finde der Insertion 6 mal näher, $15 \mathrm{mal}$ entfernter, $10 \mathrm{mal}$ gleich weit ungereben. 
Bei dem rect. intern. war das obere Ende der Insertion dem Hornhautrande näher . . . 23 mal d. i. in $71,2 \%$

$" \quad$ entfernter. . 5 , d. i. , 15,6\%
oberes und unteres Ende gleichweit 4 , d. i. , 13,2\%

Gerade umgekehrt war im grossen und ganzen das Verhalten beim externus, hier war nämlich das obere Ende der Insertion dem Hornhautrande näher . . . $6 \mathrm{mal} \mathrm{d.} \mathrm{i.} \mathrm{in} 19 \%$

$\begin{array}{cccc}, \quad \text { entfernter . . } 15 & , \text { d. i. , } 46,9 \% \\ \text { oberes und unteres Ende gleichweit } 11 & , \text { d. i. ", } 34,1 \%\end{array}$

Dabei sei bemerkt, dass ein Faden, welcher horizontal um den Bulbus gelegt wird, die Insertionslinie von internus und externus nicht halbirt; im allgemeinen ist beim Erwachsenen das oberhalb des Horizontalmeridians gelegene Stück kleiner als das untere, sowohl beim internus als auch beim externus. Bei den 5 emmetropischen Augen von Erwachsenen verhielt sich das obere zum unteren Stück

beim internus wie $1: 1,17$
beim externus wie $1: 1,07$

Nur in einem Fall war beim externus ausnahmsweise das obere Stück grösser.

Wesentlich anders sind die Verhältnisse beim Neugeborenen. Bei 14 Neugeborenen wurde das Verhalten sehr verschieden gefunden, bald war das obere Stück, bald das untere grösser, sogar an den beiden Augen desselben Individuums wurden grosse Differenzen gefunden, gelegentlich sogar rechts und links gerade das entgegengesetzte Verhalten.

Beim internus war das obere Stück

$$
\text { kleiner als das untere } 9 \mathrm{mal}
$$$$
\text { grösser " " " } 5 \text {, }
$$

Beim externus war das obere Stück

kleiner als das untere $7 \mathrm{mal}$

$\begin{array}{llll}\text { grösser " } " ~ & 4 & & \\ \text { beide gleich } & . & \mathbf{3} & ,\end{array}$


Bei nachträglicher Durchsicht der Litteratur finde ich, dass E. Fuchs bereits auf diese Verhältnisse eingegangen ist. Seine diesbezüglichen Angaben stimmen zum Teil mit den von mir erhaltenen Befunden überein, zum Teil weichen sie von denselben ab. Was die Insertionslinien von internus und externus betrifft, so erwähnt Fuchs, dass an ihnen eine Asymmetrie in zweifacher Beziehung gefunden wird. Nur ,in ungefähr der Hälfte der Fälle liegen die Insertionslinien symmetrisch zum horizontalen Meridian, so dass dieser die Insertionslinie in der Mitte traf. Wo dies nicht der Fall war, hatte sich die Insertionslinie des rectus internus nach unten verschoben. Für die Sehne des rectus externus gilt das Gegenteil. Abweichungen dieser Sehne nach unten kamen selten, viel häufiger und in höherem (trade dagegen nach oben vor. Wenn eine Asymmetrie der Insertion vorbanden war, traf es sich am häufigsten, dass die Sehne des rect. intern. nach abwärts, die des rect. extern. nach oben verschoben war. In diesem Fall mussten also die Kontraktionen des $R$. internus gleichzeitig eine leichte Senkung, die des R. externus eine Hebung des Augapfels bewirken."

„Die Insertionslinie des äusseren und inneren geraden ist auch insofern unregelmässig orientiert, als sie kaum in der Hälfte der Fälle senkrecht auf den horizontalen Meridian steht. Sehr häufig liegt nämlich die Insertionslinie des R. internus mit ibrem oberen Ende der Hornhaut näher als mit ihrem unteren. Dagegen ist die Insertionslinie des $R$. externus im umgekehrten Sinn gegen den Meridian geneigt; ihr oberes Ende liegt weiter von der Hornhaut als das untere $\left.{ }^{1}\right)$."

Diese letztere Angabe in betreff der Schrägstellung der Insertionslinien zum Hornhautrande stimmt ganz mit dem oben angegebenen überein, nicht ganz gilt das gleiche für die Asym.

1) H. Fuchs, 1. c., pag. 8 a. 9. 
metrie in Bezug auf die Lageberiehung zum horizontalen Meridian. Meine Befunde bestätigen die Verschiebung der Intermusinsertion nach unten, nicht aber die der Externusinsertion nach oben.

Erwähnt sei noch, dass Fuchs die Asymmetrie der Insertion bei super. und infer. noch häufiger und beträchtlicher fand. In der grossen Mehrzahl der Fälle kommt die grössere Hälfte der Superiorinsertion nach aussen vom vertikalen Meridian zu liegen, die Insertion des infer. fand $\mathrm{Fuchs}$ in $1 / 3$ der Fälle vom vertikalen Meridian halbiert, in den anderen Fällen gleichfalls meist nach aussen verrückt, nur selten nach innen. Beide setzen sich schief an, meist ist die Schiefstellung bedeutend und "fast stets am R. sup. und infer. in ungefähr gleichem Grade."

\section{Verhalten der Insertion der obliqui.}

Mit Rücksicht darauf, dass man neuerdings wieder den obliquis eine ganz besondere Bedeutung bei der Entwickelung der Myopie ${ }^{1}$ ) zugeschrieben hat, erscheint es angezeigt, auf das Verhalten der Insertion dieser Muskel etwas näher einzugehen. Von Fuchs ${ }^{2}$ ) werden schon ausführliche Angaben darüber gemacht. Nach ihm liegt das vordere Ende der Insertion des obliq. sup. ungefähr in demselben Meridian wie das äussere Ende des M. rẹct. sup. und zwar ersteres ungefähr ebenso viel hinter dem Äquator als letzteres vor diesem. Der absolute

1) Stilling, Über Entstehung der Myopie. Ber. über d. Verh. d. ophth. Ges, au Heidelberg. 1886.

Stilling, Untersnchungen über die Entstehung der Kurzsichtigkeit. 1887. Die von Stilling vertretene Ansicht, dass durch die Wirkung der obliq. die Myopie entstehe, ist nicht neu. M. Philipps hat schon 1840 den obliq. sup. durchschnitten, von der Meinung ausgehend, dass durch ihm die Kurzsichtig. keit entstehe.

L. A. Desmarres, Traité théorét. ot pratique des maladies des yeux.

2) Fuchs, l. c. pag. 12 u. ff. 
Wert des erwähnten Abstandes beträgt nach Fuchs 4,6 mm im Mittel (mit Schwaukungen von 0,5 bis 8,0 ). Die Sehne der bogenförmig verlaufenden Insertionslinie schliesst mit dem vertikalen Meridian einen nach vorn offenen Winkel von durchschnittlich $45^{\circ}$ ein. Das hintere Ende der Insertion liegt entweder noch an der äusseren Seite des vertikalen Meridians oder schon an der inneren Seite desselben 1 ).

Fuchs unterseheidet zwei Typen in Bezug auf die Insertionslinie des obliq. sup. Beim dem ersten Typus schlägt der von der Insertionslinie gebildete Bogen eine stark nach innen gehende Richtung ein, so dass er bald den vertikalen Meridian erreicht. Er endet stets jenseits (an der Innenseite) desselben.

In den Fällen des zweiten Typus ist die Insertionslinie kürzer und der von ihr gebildete Bogen flacher. Die Insertionslinie beginnt mehr nach vorn und verläuft mehr nach hinten und weniger nach innen; sie erreicht den vertikalen Meridian nicht, sondern endigt nach aussen vor demselben. Beim orsten Typus nähert sich die Lage der Insertionslinie der äquatorialen, beim zweiten Typus der meridionalen Richtung. Der zweite Typus soll vorzugsweise bei myopischen Augen vorkommen. Den ersten Typus sieht Fuchs als die ursprüngliche normale Anheftungsform an, sie fand Fuchs auch an den Augen von Neugehorenen. Die "myopische" Anheftungsform sei als die abnorme zu betrachten. Nach Fuchs soll die "myopische" Anheftungsform aus der ursprünglichen dadurch entstehen, dass bei der Einwärtswendung des Auges ,die nach innen an-

1) Wenn $S$ tilli ing (Ophth. Kongr. 1886, pag. 16) angiebt, dass der obliquus sup., indem er schrïg oder, was selten vorkommt, beinahe median verläuft, manchmal Ausläufer nach dem Sehnerven zu schicke, die in einigen Fallen dicht an den "Sehnerven herangehen", und dass in anderen Fällen sie sich davon entfernt halten, in wieder anderen Fällen am äusseren Umfang des Sehnerven vorbeigehen", so haben mir meine Untersuchungen für dieses Verhalten keine Bestätigung ergeben. Auch von Fuchs findet ein derartiges Verhalten keine Erwähnumg. 
gehefteten Sehnenfasern am stärksten gespannt werden", woru gleichzeitig noch die Kontraktion des obliq. sup. hinzutritt bei Konvergenz mit gesenkter Blickebene. „Es wäre denkbar sagt Fuchs - dass die stärkst gedehnten inmersten Fasern allmählich atrophierten, während sich neue Fasern arn vorderen Rande der Sehne ausbildeten." Ob dieser Erklärungsversuch von Fuchs richtig ist, lasse ich dahingestellt; jedenfalls spricht manches gegen eine solche Annahme. Wenn durch ausgedehntere Untersuchungen der Nachweis geliefert wird, dass der zweite Typus der Anheftungsform des obliq. super. beim Neugeborenen und dem kindlichen Auge nicht gefunden wird, ebenso im allgemeinen auch nicht beim emmetropischen und hypermetropischen Auge des Erwachsenen, sondern ausschliesslich nur beim myopischen Auge, alsdann wäre die Bezeichnung "myopische"s Anheftungsform begründet. Für diesen Fall dürfte aber doch die Annahme näher liegen, dass die abweichende Anheftungsform mit der Formveränderung des myopisch gewordenen Auges in Zusammenhang steht.

Nach meinen Untersuchungen liegen die Verhältnisse so:

Die Insertion der obliqui wird nicht nur beim Erwachsenen sondern auch beim Neugeborenen ungemein wechselnd gefunden. Was die Insertion des obliquus superior betrifft, so wurde ihre Länge, d. i. der Abstand von dem einen Ende der Insertion bis zu dem anderen,

beim Neugeborenen im Mittel $=7,26 \mathrm{~mm}$ gefunden

$$
(\operatorname{Max} .=9,75, \text { Min. }=5,5)
$$

beim erwachsenen Emmetropen im Mittel $=10,6$

$$
(\text { Max. }=11,5, \text { Min. }=10,0) \text {. }
$$

Die Richtung der Insertionslinie war ungemein verschieden; sowohl an den Augen der Neugeborenen als auch an denen der emmetropisehen Erwachsenen hatte die Insertionslinie bald eine mehr äquatoriale, bald eine mehr meridionale bezw. eine mehr schräge Richtung, welche die Mitte zwischen beiden Typen einhielt, 
öfters in der Art, dass das vorderste grössere temporale Stück der Insertion eine mehr meridionale Richtung hatte, das kleinere hintere Stück eine mehr äquatoriale.

Im allgemeinen ist der Verlauf der Insertionslinie so, dass dieselbe mehr oder weniger dicht hinter dem lateralen Ende der Insertion des rectus superior auf der temporalen Seite beginnt und bogenförmig nach hinten und nasalwärts verläuft. Je nachdem die Insertionslinie nun eine mehr äquatoriale oder eine mehr meridionale Richtung hat, überschreitet sie bald früher bald später den Vertikalmeridian und setzt sich gewöhnlich noch ein Stück weit auf die nasale Seite fort. In nicht wenigen Fällen erreicht das mediale Ende der Insertion gerade den Vertikalmeridian, überschreitet denselben aber nicht, relativ selten bleibt die ganze Insertionslinie auf der temporalen Seite von dem Vertikalmeridian noch etwas entfernt.

Aus dem eben Gesagten ergiebt sich von selbst, dass der Vertikalmeridian die Insertionslinie in sehr ungleichem Verhältnis schneidet; bei ausgesprochen vorherrschend äquatorialer Richtung ist der nasalwärts vom Vertikalmeridian gelegene Teil der Insertionslinie verhältnismässig gross, umgekehrt bei mehr meridionaler Richtung klein bezw. ganz fehlend. Während bei vorherrschend meridionaler Richtung der Insertion beim erwachsenen Emmetropen das temporalwärts vom Vertikalmeridian gelegene Teilstück der Insertionslinie in zwei Fällen exheblich grösser war als das nasalwärts gelegene, waren bei mehr äquatorialer Richtung einmal beide Teilstücke ziemlich gleich gross, in einem Fall sogar das nasalwärts gelegene Stück grösser. Bei allen untersuchten fünf Augen von emmetropischen Erwachsenen ging die Insertionslinie mehr oder weniger weit über den Vertikalmeridian herüber auf die nasale Seite. Anders bei Neugeborenen; hier eudete in einigen Fällen die Insertionslinie im Vertikalmeridian, überschritt denselben aber nicht auf die nasale Seite herüber. Bei vorherrschend äquatorialer Richtung waren 
beide Teilstücke gelegentlich gleich gross, im allgemeinen war das temporale Teilstück etwas grösser; in den oben genannten Fällen, in denen die Insertionslinie in dem Vertikalmeridian endete, lag selbstverständlich die ganze Insertionslinie auf der temporalen Seite.

Bei der angegebenen grossen Mannigfaltigkeit in Bezug auf Richtung der Insertionslinie ist es nicht gut angängig, aus den Einzelmessungen Durchschnittswerte zu berechnen.

Um die Neigung der Insertionslinie einesteils zum Vertikalmeridian, anderenteils zum Äquator zu bestimmen, wurde von den beiden Endpunkten der Insertion sowohl die Entfernung vom Äquator als auch vom Vertikalmeridian gemessen. Es geschah dies in der Art, dass zu einem feinen Faden gemessen wurde, welcher im Äquator bezw. im Vertikalmeridian um den Bulbus gelegt wurde. Denkt man sich eine Linie durch die beiden Endpunkte der Insertion gelegt, so stellt diese die Sehne der bogenförmig verlaufenden Insertion dar. Aus den erhaltenen Messungswerten berechnet sich nun der Neigungswinkel dieser Bogensehne zum Vertikalmeridian sehr wechselnd beim erwachsenen Emmetropen schwankte der

Winkel zwischen . . . . . . . $30^{\circ}$ und $62^{\circ}$ und beim Neugeborenen zwischen . . . . $35^{\circ}$ und $67^{\circ}$ und der Neigungswinkel der Bogensehne zum Äquator

beim erwachsenen Emmetropen zwischen $20^{\circ}$ und $53^{\circ}$ "Neugeborenen, $21^{\circ}$ und $63^{\circ}$

Bei dem individuell so überaus verschiedenen Verlauf der Insertionslinie haben berechnete Mittelwerte wenig Wert. Wird aus den Einzelmessungen das Mittel gewonnen, so erhält man bei den erwachsenen Emmetropen als Mittelwert für den Neigungswinkel der Bogensehne zum Vertikalmeridian einen Winkel von ca. $48^{01}$ ), bei dem Neugeborenen von ca. $50^{\circ}$.

1) Fuch s giebt denselben $z u 45^{\circ}$ an. 
Die so überaus verschiedene Richtung der Insertionslinie der obliqui dürfte in Zusammenhang stehen mit der Verschiedenheit in der Konfiguration der Orbita, der Lage der Trochlea und insbesondere auch mit der Lage des Bulbus in der Orbita.

Nicht unerwähnt will ich lassen, dass bei mehreren Augen von jugendlichen Individuen in exquisiter Weise der von Fuchs beschriebene zweite Typus der Insertion zu sehen war, bei dem nämlich die Insertion eine meridionale Richtung hatte und das hintere Ende der Insertion etwas entfernt vom vertikalen Meridian auf der temporalen Seite lag. Der Form und Grösse nach handelte es sich bei diesen Augen offenbar nicht um myopische Augen; ob solche Augen mehr zur Entwickelung von Myopie disponieren, muss dahingestellt bleiben.

Jedenfalls geht aus dem Mitgeteilten hervor, dass der sog. „,myopische" Typus der Insertion des obliq. super. auch beim nicht myopischen kindlichen Auge vorkommt, die mehr meridionale Richtung der Insertion bei dem Auge des Neugeborenen nichts ungewöhnliches ist.

Auf das Verhalten bei myopischen Augen werde ich an anderer Stelle eingehen, hier sei nur erwähnt, dass - was auch schon Fuchs angiebt - der erste Typus in exquisiter Weise ausgeprägt auch beim hochgradig myopischen Auge gefunden wird.

Was die Beziehung des vorderen (lateralen) Endpunktes der Insertion des obliquus superior zu dem lateralen Endpunkt der Insertion des rectus superior betrifft, so lagen beide bei sämtlichen untersuchten emmetropischen Augen von Erwachsenen ziemlich in gleichem Meridian. Der Abstand beider betrug beim Erwachsenen im Mittel 4,1 $\mathrm{mm}^{2}$ ) (Max. 6,5, Min. 3). Dabei sei erwähnt, dass das vordere Ende der Insertion des obl. super. beim Frwachsenen 4 mal im Äquator lag, in einem Fall $3 \mathrm{~mm}$

1) Nach Fuchs im Mittel 4,6 (Max. 8, Min. 0,5). 
dahinter, während das hintere Ende der Insertion im Mittel 6,9 (Max. 8, Min. 5) hinter dem Äquator lag.

Bei dem Neugeborenen betrug der erwähnte Abstand von Insertion des rect. super. und obliq. super. im Mittel $2 \mathrm{~mm}$ (Max. 3,25, Min. 1,0) und zwar stets im gleichen bezw. beinahe gleichen Meridian. Das vordere Ende der Insertion des obliq. super. lag durchschnittlich 1,12 $\mathrm{mm}$ hinter dem Äquator (Max. $3 \mathrm{~mm}$ hinter dem Äquator, Min. im Äquator), das hintere Ende der Insertion im Mittel 5,39 mm hinter dem Äquator (Max. 6,25, Min. 5).

Was die Insertion des obliquus inferior betrifft, so bietet auch sie ein sehr wechselndes Verhalten. Die Länge der Insertionslinie, von dem vorderen bis zum hinteren Endpunkt derselben gemessen, beträgt beim Erwachsenen (Emmetropen) im Mittel 11,45 (Max. 13, Min. 10,5), beim Neugeborenen 7,08 (Max. 8, Min. 6). In den meisten Fällen liegt das vordere Ende der Insertion unweit hinter dem Äquator und etwas unterhalb von dem Horizontalmeridian ungefähr in gleicher Höhe mit dem unteren Rand der Insertion des rectus externus bezw. etwas darüber. Von hier aus steigt die Insertionslinie meist schräg auf, kreuzt den horizontalen Meridian und endet rückwärts etwas oberhalb dieses Meridians. Dabei sei bemerkt, dass die Insertionslinie sehr gewöhnlich nicht gleichmässig schräg nach oben und hinten zieht, sondern innerhalb ihres Verlaufes Unregelmässigkeiten zeigt. An ihrem vorderen Ende sieht man gelegentlich mehrere kleine annähernd parallel zu einander gestellte Insertionsleisten meist in der Art, dass vor bezw. nach unten von einer grösseren Insertionslinie, die im grossen und ganzen die Richtung der übrigen zusammenhängenden Insertion hat, zwei kleinere Partialinsertionsleistchen zu sehen sind. Die von diesen letzteren entspringenden Muskelbündel verschmelzen unweit von der Insertion mit der Hauptmasse des Muskels. Während, wie eben angegeben, gewöhnlich die Insertion von 
unten vorn nach hinten oben schräg aufsteigt, wurde in einem Fall bei einem erwachsenen Emmetropen gerade der entgegengesetzte Verlauf von oben vorn nach unten hinten gesehen. (Auch Fuchs [1. c. p. 18] hat das Gleiche beobachtet.)

Was das Verhalten der Insertion zum horizontalen Meridian betrifft, so teilt derselbe in den meisten Fällen die Insertionslinie und zwar derart, dass bei den Erwachsenen das vordere unterhalb gelegene Stück gewöhnlich erheblich grösser ist als das mehr rückwärtig gelegene. Das hintere Ende der Insertion fiel gelegentlich sowohl bei Erwachsenen als auch bei Neugeborenen in den horizontalen Meridian.

Denkt man sich eine Linie gelegt durch die beiden Endpunkte der Insertion, so bildet diese Linie mit dem Horizontalmeridian einen nach vorn offenen. Winkel beim Neugeborenen von $17^{\circ}-57^{\circ}$, beim Erwachsenen von $16^{\circ}-30^{\circ}$; in dem einen Fall, in welchem bei einem erwachsenen Emmetropen die Richtung der Insertion eine dem gewöhnlichen gerade entgegengesetzte war, bildete die erwähnte Verbindungslinie der Endpunkte der Insertion mit dem Horizontalmeridian einen nach hinten offenen Winkel von $25^{\circ}$.

Wie erwähnt, liegt das vordere Ende der Insertion meist unweit hinter dem Äquator. Genauere Messungen ergaben, dass beim Erwachsenen das vordere Ende der Insertion im Mittel 4,1 mm (Max. 6,5, Min. 3) hinter dem Äquator liegt, das hintere Ende 13,6 im Mittel (Max. 15, Min. 12,5). Beim Neugeborenen betrugen die betreffenden Entfernungen im Mittel 3,25 (Max. 4,25, Min. 2) und 8,2 mm (Max. 10, Min. 6,25).

Der Winkel, welchen die Verbindungslinie der Insertionsendpunkte mit dem Äquator bildet, variiert beim Erwachsenen zwischen $43^{\circ}$ und $67^{\circ}$, beim Neugeborenen zwischen $32^{\circ}$ und $62^{\circ}$.

Das vordere Ende der Obliquusinsertion lag hinter der Insertion des rect. extern. im Mittel $6,37 \mathrm{~mm}$ beim Neugeborenen (Max. 7,25, Min. 5,5) und 10,21 im Mittel beim Frwachsenen 
Tabelle X.

\section{Verhalten der Insertion der Obliqui.}

\begin{tabular}{|c|c|c|c|c|c|c|c|c|c|c|c|c|}
\hline \multirow{4}{*}{ Name und Alter des Kindes } & \multicolumn{5}{|c|}{ Obliquus superior } & \multicolumn{5}{|c|}{ Obliquus inferior } & \multirow{2}{*}{\multicolumn{2}{|c|}{$\begin{array}{c}\text { Sehnen- } \\
\text { abstend } \\
\text { der } \\
\text { obliqui }\end{array}$}} \\
\hline & \multirow{3}{*}{ 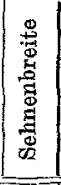 } & \multicolumn{4}{|c|}{ Abstand der Sehne } & \multirow{3}{*}{ 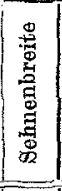 } & \multicolumn{4}{|c|}{ Abstand der Sehne } & & \\
\hline & & \multicolumn{2}{|c|}{$\begin{array}{l}\text { vom Horn- } \\
\text { hautrand }\end{array}$} & \multicolumn{2}{|c|}{$\begin{array}{c}\text { vom } O p \text { m } \\
\text { ticus }\end{array}$} & & \multicolumn{2}{|c|}{$\begin{array}{c}\text { vom Horn- } \\
\text { hautrand }\end{array}$} & \multicolumn{2}{|c|}{$\begin{array}{c}\text { vom } 0 p-1 \\
\text { tieus }\end{array}$} & \multirow{2}{*}{ 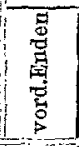 } & \multirow{2}{*}{ 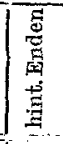 } \\
\hline & & $\underset{0}{\mathbb{B}}$ & 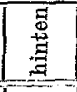 & है & 莺 & & 居 & 递 & 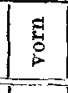 & 量 & & \\
\hline eugeb. Wöchner, Asyl RA & 8 & 10.75 & 11 & 8 & 5 & 6.5 & 10 & 12.5 & 9.5 & 5 & 9 & 9 \\
\hline r. 104, Neugeborener, RA & 3.5 & 9.3 & 11 & 9.75 & 5 & 7.5 & 9.75 & 14.5 & 9.5 & 2.25 & 10.3 & 8.5 \\
\hline LA & 5.5 & 8.5 & 11.25 & 9.25 & 5 & 5.75 & 10.5 & 14 & 8.25 & 4 & 11 & 7.25 \\
\hline Nr. 98, Neugeborener, RA & 7 & 10 & 13 & 11 & 5.5 & 6.6 & 11 & 145 & 9 & 4. & 10.25 & 57.5 \\
\hline $\begin{array}{r}\text { eageborenes Kind (bei der Ge- } \\
\text { buxt erstickt) RA }\end{array}$ & 15.5 & 9.5 & 12.5 & 9 & 4.25 & & 10.75 & $13 . g$ & 7.75 & 3.75 & 5 & 4.2 \\
\hline 2 Tage altes Kind, RA & 4.5 & 11 & 13.25 & 10 & 5.5 & 6.75 & $11 . \mathrm{g}$ & 14 & 9.5 & 3.25 & 10.3 & 6.3 \\
\hline Tage alter Knabe, RA & 5.75 & 8 & 11 & 9.3 & 5 & 7 & 10 & 12 & 8 & 3 & 9.25 & 6 \\
\hline LA & 7 & 6.75 & 11 & 9.25 & 4 & 6.5 & 9.75 & 12.3 & 7 & 3 & 9.75 & 5 \\
\hline Karl G., 5 Tage alt, RA & 8.5 & 10 & 11.3 & 9 & 6 & 6.75 & 11.5 & 14 & 7 & 2.3 & 9.75 & 8.5 \\
\hline LA & 8 & 10 & 12 & 9.5 & 4 & 7 & 12 & 14 & 8 & 4 & 10 & 75 \\
\hline Nr. 105, 3 Tage alt, Kind, RA & 5 & 10 & 11.5 & 8.5 & 5 & 5.5 & 10 & 13 & 9 & 4 & 10 & 7 \\
\hline LA & 5.25 & 10 & 12 & 8 & 4 & 6 & 10 & 13 & 8 & 4 & 10 & 7 \\
\hline $\begin{array}{r}\text { Ir. 99, Neugeborener, } 4 \text { 'Tage } \\
\text { alt, LA }\end{array}$ & 5.3 & 8.25 & $5 \mid 12.5$ & 19 & 4.5 & 6 & 11 & 1135 & 8 & 3 & & \\
\hline Nr. 250, Neugeborener, 5 Tage & & & & & & & 11 & 10.5 & 10 & & 10 & \\
\hline Mittel bei Neugebc & 7 & 9 & 10.3 & 9 & 4.25 & 8 & 9 & 13 & 10 & 4 & 11 & 9.25 \\
\hline $\begin{array}{l}\text { aus 14 Fällen) } \\
\text { Nr. 103, Neugeborener, } 20 \text { Tage }\end{array}$ & 6,41 & 9.36 & 11.68 & 9.18 & 4.78 & 6.49 & 10.44 & 13.05 & 8.42 & 3.54 & 9.65 & 7.11 \\
\hline & 5 & 9 & 12.5 & 9.5 & 5 & 5.5 & 11 & 13.25 & 9 & 3 & 10.25 & 7 \\
\hline Knabe L., 2 Monat, RA & 8 & 10.5 & 12.5 & 9 & 4 & 6.5 & 11.5 & 14.5 & 9.5 & 3 & 10 & 7 \\
\hline LA & 7 & 11 & 12.5 & 8.5 & 4.5 & 5 & 11.5 & 14 & 7 & 3 & 9 & 7 \\
\hline monatliches Kind, $\mathrm{RA}$ & 7.3 & 10 & 13.5 & 10.6 & 5.5 & 6 & 12 & $1 \tilde{3}$ & 9 & 4.3 & 10 & 7.5 \\
\hline LA & 8 & 11 & 14 & 11 & 5 & 7 & 13 & 16 & 9 & 4 & 10 & 6.5 \\
\hline Louise R., $3^{1}$ Monat, RA & 6.3 & 11 & 15 & 10 & 4 & 7 & 12.5 & 15.3 & 10 & 4.3 & 10 & 7 \\
\hline LA & 8 & 10 & 14 & 10 & 5 & 8 & 13.5 & 15.5 & 9.5 & 4 & 11 & 7 \\
\hline ina $J_{.}$, & 6.25 & 10.5 & 12.25 & 9 & 5 & 5.25 & 12 & 15 & 7 & 3 & 8.5 & 8.5 \\
\hline 11 monatliches Kind. RA & 5.5 & 11 & 10.5 & 8 & 5 & 6 & 11.5 & 14.5 & 8 & 3.75 & 10.5 & \\
\hline LA & 16 & 11 & 11.5 & 8.5 & 5 & & 12 & 14 & 8.5 & 4 & 10.5 & 8.5 \\
\hline$A$ & 7 & 11.3 & 14.5 & 10 & 5.75 & & 13 & 15 & 10.5 & 3.75 & 12 & 7.5 \\
\hline amillus $\mathrm{H}, 1^{1 / 2} \mathrm{Jahr}, \mathrm{RA}$ & 8.5 & 13 & 15.5 & 11.75 & 6.5 & 7.75 & 14 & 18 & 11.5 & 5.5 & 13 & 10.5 \\
\hline
\end{tabular}




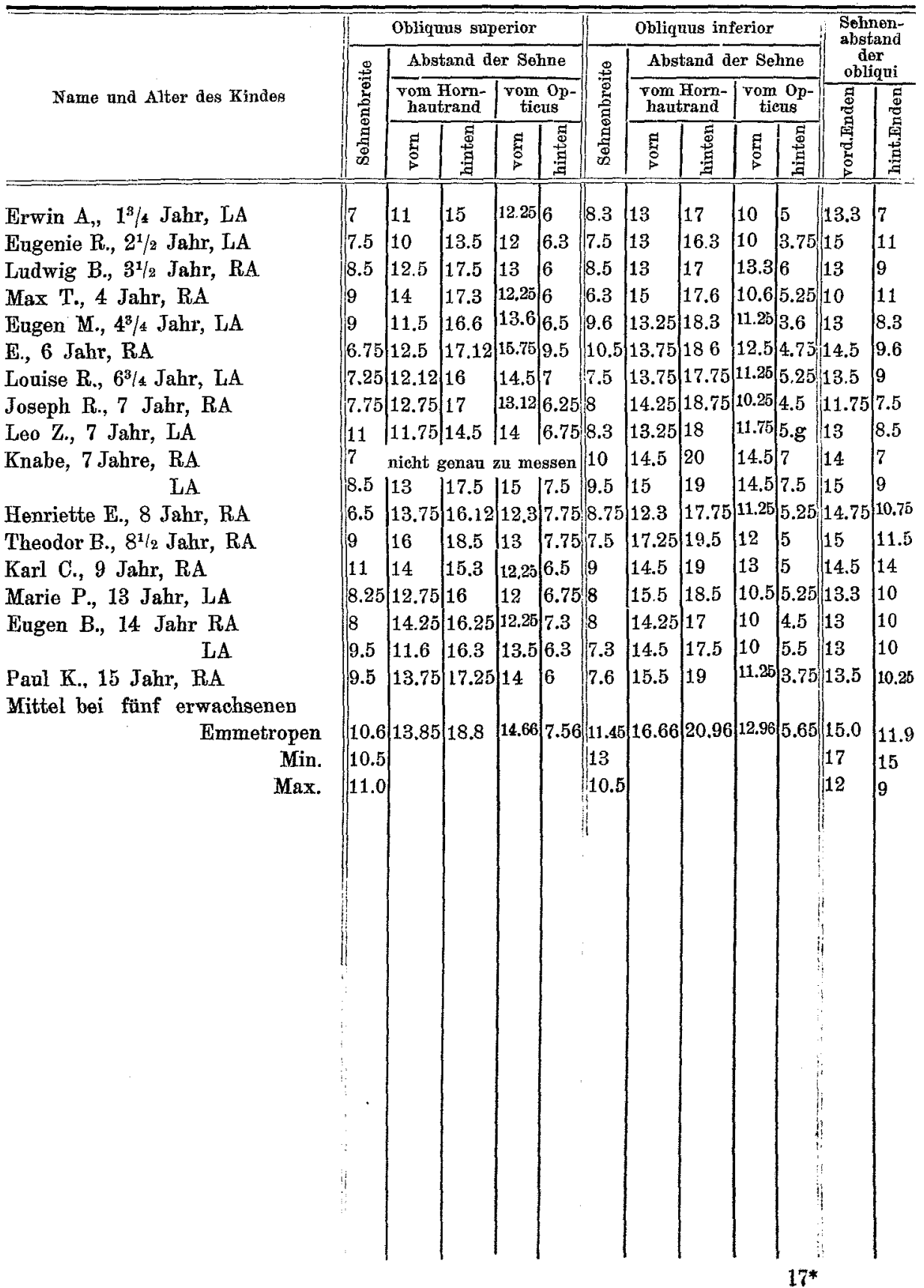


(Max. 11,75, Min. 9). Zieht man von dem vorderen Ende der Obliq. inferorinsertion im gleichen Meridian eine Linie nach vorn, so schneidet diese die Externusinsertion zum öfteren an der Grenze des unteren Drittels, seltener in der Mitte bezw. etwas tiefer nahe dem unteren Rand.

Wird der Abstand je der beiden vorderen und der beiden hinteren Endpunkte der Insertionen des obliqui sup. und obliq. infer. gemessen, so erhält man sehr differente Messungswerte; hat die Insertion des obliq. sup. eine mehr meridionale Richtung, so konvergieren beide Insertionslinien nach hinten, im anderen Fall hat der von den beiden Obliquusinsertionen begrenzte Raum sehr mannigfache Form. Bei den untersuchten fünf emmetropischen Augen von Erwachsenen betrug der Abstand der korrespondierenden vorderen Endpunkte im Mittel 15 (Max. 17, Min. 12) der correspondierenden hinteren Endpunkte im Mittel 11,9 (Max. 15, Min. 9), beim Neugeborenon 9,7 im Mittel (Max. 10, Min. 9) und 6,6 (Max. 9,75, Min. 4,75).

Bei den grossen individuellen Verschiedenheiten im Verhalten der Obliquusinsertionen war es bei der relativ kleinen Zahl von Untersuchungen nicht möglich, Unterschiede festzustellen, welche im Zusammenhang mit den Wachstumsverhältnissen des Auges stehen.

Das nähere Verhalten der Obliquusinsertionen am wachsenden Auge ist aus beistehender Tabelle (Tabelle $\dot{\mathrm{X}}$ ) ersichtlich.

\section{Erklärung der Tafeln.}

Tafel XXXI. Graphische Darstellung des Wachstums von Auge und Gehirn.

Tafel XXXII/XXXIII. Serie von Abbildungen von Angen versehiedener Lebensalter. 